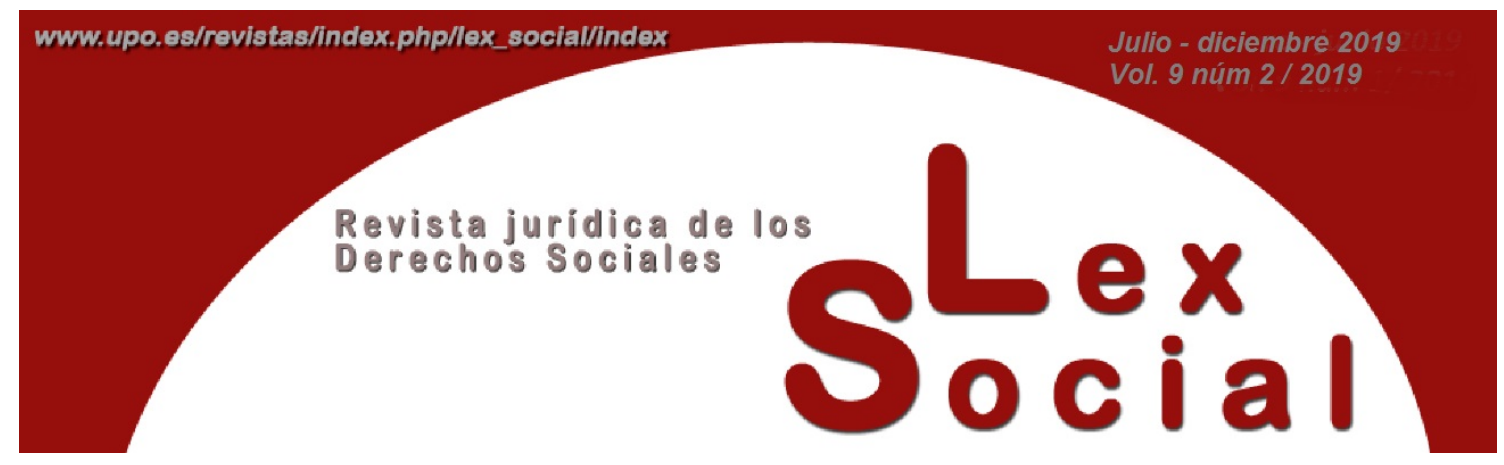

\title{
PROTECCIÓN SOCIAL DEL SERVICIO DOMÉSTICO DESDE UNA PERSPECTIVA DE GÉNERO
}

\section{SOCIAL SECURITY PROTECTION OF THE DOMESTIC WORK FROM A GENDER PERSPECTIVE}

\author{
MARÍA ANGUSTIAS BENITO BENITTEZ \\ Derecho del Trabajo y Seguridad Social \\ Universidad de Cádiz
}

Artículo recibido el 26 de abril de 2019

Artículo aceptado el 27 de mayo de 2019

\section{RESUMEN}

En una actividad en la que las mujeres representan más del $90 \%$ de los trabajadores, resulta indiscutible que su regulación debe superar el filtro del principio de igualdad y no discriminación por razón de sexo. El estudio que se presenta tiene por objetivo abordar la protección social del servicio al hogar familiar integrando la dimensión de género. Resulta esencial dado que quizás sea esta actividad la que en mayor medida la formulación de la Seguridad Social ha sido determinante en la generación de la brecha de género que ha caracterizado (aún hoy) al servicio doméstico. La reforma que tuvo lugar en 2011 se presentaba como un innegable avance en el plano formal que debía de propiciar el correlativo progreso material. Nos dispondremos a analizar en qué medida se está logrando tales objetivos, así como las carencias y reticencias que aún subsisten y que obstaculizan alcanzar o, al menos, impulsar la igualdad de oportunidades.

Palabras clave: Servicio doméstico, protección social, seguridad social, igualdad, perspectiva de género. 


\begin{abstract}
In an activity in which women represent more than $90 \%$ of workers, it is undeniable the need to design policy to adopt gender mainstreaming in social protection interventions targeting domestic workers. This paper analyses the Spanish Social Security system of the domestic work from a gender mainstreaming. This perspective is essential because the formulation of the Social Security has been a significant factor in generating the gender gap that has characterized (still today) domestic service. The reform that took place in 2011 was presented as an undeniable advance in the formal dimension that should promote the substantive equality. It discusses the extent to which goals are being achieved, as well as the deficiencies that still exist and that hinder to achieve, or at least promoting, the equality of opportunities.
\end{abstract}

KEYWORDS: Domestic workers, social protection, social security, equal rights, gender mainstreaming.

SUMARIO

1.- Un punto de partida: la feminización del servicio al hogar familiar

2.- La prohibición de discriminación por razón de sexo como principio impulsor de una protección social al servicio de la igualdad de oportunidades

3.- El acceso al sistema especial: el régimen de encuadramiento y cotización

4.-La apertura a las contingencias profesionales: el inicio de un camino inacabado hacia la igualdad

5.- La acción protectora del sistema especial de empleadas del hogar

5.1.- La protección de la incapacidad temporal: debilidades y fortalezas

5.2.- Las pensiones de incapacidad permanente y jubilación: manifestación de una brecha de género sui generis

5.3.-La protección de desempleo: el alcance de una persistente discriminación directa 


\section{1.- UN PUNTO DE PARTIDA: LA FEMINIZACIÓN DEL SERVICIO AL HOGAR FAMILIAR}

Resulta indiscutible que la discriminación que sufren las mujeres en el mercado de trabajo (brecha salarial, sobrerrepresentación femenina en el trabajo a tiempo parcial, en puestos vinculados a los roles tradicionalmente femeninos y en trabajos no remunerado -tareas domésticos y cuidados de familiares-) es uno de los factores que explica la peor posición que ocupan en del sistema de Seguridad Social. Pero no debe pasarse por alto también que ha sido la propia articulación jurídica del sistema la que ha penalizado y penaliza a las mujeres. En virtud del principio de transversalidad de género, el sistema de Seguridad Social debe constituir un instrumento que debe dirigirse a avanzar en la igualdad de oportunidades, dada la importancia que adquiere la protección que dispensa en la garantía de la autonomía económica femenina que implica, en definitiva, la independencia social y el empoderamiento de las mujeres. Desde esta última óptica, el principio de transversalidad de género exige una reformulación de los tratamientos cuestionables que presenta el sistema de Seguridad Social, siendo la regulación recibida por el servicio del hogar familiar un ámbito recurrente en la recreación de discriminaciones sexistas.

Resulta suficiente partir de una premisa cuantitativa, estructural de esta actividad: se trata de una actividad feminizada, en la que las mujeres representan un porcentaje próximo al 90 por ciento ${ }^{1}$. Esta presencia masiva, pretérita y actual de mujeres, implica que cualquier debate, análisis doctrinal científico y/o jurisprudencial, o procedimiento de generación legislativo, exija de la aplicación del principio de transversalidad de género, pues toda actuación que se adopte generará un impacto indiscutible sobre las mujeres. No existe en nuestro mercado de trabajo otra actividad laboral legalizada que requiera, sin discusión alguna, de una presencia reforzada del principio de igualdad y no discriminación por razón de género.

La OIT considera que el trabajo de cuidados y los trabajadores del cuidado es un elemento clave para un futuro con trabajo decente directamente relacionado con la consecución de la igualdad de género. Destaca que el trabajo doméstico adquiere importancia en varios contextos: cuando concurre una insuficiencia de servicios de cuidado públicos; cuando los sectores más prósperos de la población tienen el poder económico para subcontratar la prestación de cuidados a otro grupo de la población que dispone de menos medios económicos; cuando se adoptan programas de trabajadoras y trabajadores extranjeros orientados específicamente a los cuidados facilitando su contratación y empleo por parte de hogares privados; cuando las políticas públicas proporcionan incentivos y subsidios para alentar a las personas a contratar a trabajadores y trabajadoras del cuidado; y cuando las relaciones de trabajo y las

\footnotetext{
${ }^{1}$ Si acudimos a la EPA (2018T4), “Ocupados por sexo y rama de actividad. Valores absolutos y porcentajes respecto del total de cada sexo" estima que, para la categoría de "actividades de los hogares como empleadores de personal doméstico; actividades de los hogares como productores de bienes y servicios para uso propio”, de los 616,9 miles de personas trabajadoras domésticas, 548,6 miles son mujeres.
} 
condiciones de trabajo en los hogares privados están, de jure o de facto, insuficientemente reglamentadas o no reglamentadas en absoluto ${ }^{2}$.

\section{2.-LA PROHIBICIÓN DE DISCRIMINACIÓN POR RAZÓN DE SEXO COMO PRINCIPIO IMPULSOR DE UNA PROTECCIÓN SOCIAL AL SERVICIO DE LA IGUALDAD DE OPORTUNIDADES}

Si nos remontamos a la regulación del contrato de servicio doméstico en el Código Civil de 1889, observamos que el tratamiento que por entonces se otorgaba, no era sino la plasmación jurídica de la desigualdad social existente. Consideradas como criadas, cercanas a un derecho de propiedad del amo, su necesaria incorporación al ámbito familiar para realizar la prestación de servicios determinó una serie de características que han permitido a lo largo de su evolución jurídica un desbordamiento de las notas de subordinación y dependencia. Tres son los rasgos definitorios del servicio doméstico en la regulación civilista: (1) el carácter fiduciario, que adquiere su máxima manifestación en la posibilidad de extinción de la relación sin causa y antes de término; (2) desigualdad jurídica entre las partes, en una relación de plena superioridad por parte del amo; (3) y, la necesidad de normas de derecho público en las relaciones entre amo y criado, reveladora de la necesidad de limitar la autonomía de la voluntad de las partes contratantes ${ }^{3}$.

Una actividad marcada por su carácter servil y la desvaloración social que sería incrementada por la agonía legislativa hacia el reconocimiento de la laboralidad de la relación que no tuvo lugar, pese a los numerosos intentos, hasta la promulgación del Estatuto de los Trabajadores en 1980. Se asumiría normativamente que el servicio al hogar familiar es una relación jurídica en la que concurren los elementos propios del contrato de trabajo, esto es, se trata de una prestación libre y personal de servicios, por cuenta y bajo la dirección de otra persona, y a cambio de una remuneración. Ahora bien, la singularidad material existente en tal relación laboral justificó un tratamiento diferenciado amparado bajo la consideración de especial, que vendría regulado por el Real Decreto 1424/1985, de 1 de agosto ${ }^{4}$, que situaba en el hogar familiar el factor determinante para la introducción de las especialidades en relación a lo previsto en la legislación común.

Tales especialidades justificó, desde entonces y hasta ahora, un desequilibrio jurídico de las partes, pese a los intentos de limitar la autonomía de la que disfrutaban en la configuración de la relación laboral, que pivota en el mantenimiento de uno de los aspectos más paradigmáticos de la misma, su régimen extintivo. Es por ello que, y pese a la actual regulación, el fundamento jurídico en el que se basa su especialidad queda intacto.

\footnotetext{
${ }^{2}$ OIT, “El trabajo de cuidados y los trabajadores del cuidado para un futuro con trabajo decente”, 2018.

${ }^{3}$ Quesada Segura, R., El contrato de servicio doméstico, La Ley, 1991, pp. 28 y 29.

${ }^{4}$ Real Decreto 1424/1985, de 1 de agosto, por el que se regula la relación laboral de carácter especial del Servicio del Hogar Familiar.
} 
La singularidad material en la que se sustenta tales especialidades deriva de la existencia de una conexión entre las esferas privadas de las partes al introducirse y participar una de ellas, la empleada, en el ámbito familiar de la otra, el empleador, cualificándolo como un contrato fiduciario. En efecto, en el servicio al hogar familiar una persona, la empleada, se introduce en el ámbito personal, privado y familiar de otra, ocasionándose una colisión de derechos: entre aquellos fundamentales, la intimidad personal y familiar, y la inviolabilidad de domicilio (artículos 18. 1 y 2 CE); y los derechos constitucionales reconocidos a los trabajadores y trabajadoras, entre ellos, el derecho al trabajo (artículo $35 \mathrm{CE}$ ) y el derecho a la seguridad e higiene en el trabajo (artículo 40.2 CE). La clave de la especialidad se situaría en "el ámbito de prestación de los servicios -para el hogar familiar- y en estrecha conexión con el mismo, la índole de aquéllos, eminentemente personales, con acentuación del principio de mutua confianza entre las partes" ${ }^{5}$. La confianza se convierte en un principio transcendental que es exigencia para el funcionamiento de la relación, y no en un mero planteamiento normativo ${ }^{6}$. Ahora bien, y pese a que estemos de acuerdo que tal argumentación puede originar adaptaciones en la regulación jurídica, la que tuvo lugar con el RD 1424/1985, de 1 de agosto, no hizo sino tomar tal discurso para ofrecer una plena habilitación a los empleadores en la fijación de las condiciones laborales, situándoles en una posición privilegiada que ha fortalecido la desvaloración de este empleo: "la confianza «soluciona», es decir, enmascara y cubre las relaciones de poder y las cuestiones que debieran tratarse en términos de derechos"7 . Ello motivó que muchos de sus elementos fueran sometidos al juicio de igualdad y no discriminación por razón de género, reprochándose de manera reiterada y constante que los mismos eran susceptibles de constituir discriminaciones indirectas, en la medida en que no resultaban admisibles las posibles justificaciones dadas a tales tratamientos, demandándose una reformulación de sus contenidos.

Pese al incuestionable avance que se ha logrado con la nueva regulación del 2011, especialmente, en materia de la delimitación del ámbito subjetivo, salarios, o, de la jornada laboral, la prioridad que se sigue otorgando al carácter personal de la relación ha mantenido indemne la posibilidad de proceder a un desistimiento ad nutum, esto es, sin justificación de su causa, y ello porque "toda resolución judicial que acabe imponiendo la readmisión in natura y, por ende, obligatoria de un empleado o empleada de hogar en el domicilio familiar interfiere indefectiblemente en el derecho, también constitucionalizado como fundamental, a la intimidad personal y familiar (artículo 18.1 de la Constitución)" ${ }^{\text {. }}$. Lo anterior implica que, producida la ruptura de la confianza surge una colisión de derechos, resulta imposible exigir a la persona empleadora y a los miembros de su ámbito familiar la imposición de una persona ajena

\footnotetext{
${ }^{5}$ STSJ de Cantabria, núm. 524/2000, de 11 mayo.

${ }^{6}$ Quesada Segura, R., El contrato de servicio doméstico, op.cit., p.78.

${ }^{7}$ Mestre i Mestre, R.M., “Trabajadoras de cuidado. Las mujeres de la Ley de Extranjería”, Mujeres en el camino. El fenómeno de la migración femenina en España, Checa y Olmos, F., (de), Antrazyt, 2005, p. 145.

${ }^{8}$ STSJ de Madrid, núm. 8610/2008, de 24 de noviembre de 2008.
} 
a su esfera privada y personal. Singularidad que alcanza a aquellas extinciones declaradas judicialmente nulas, por ejemplo, cuando la decisión está vinculada a la maternidad. En estos casos, la intimidad del hogar familiar, impide que se aplique como sanción la readmisión de la trabajadora ${ }^{9}$.

En el ámbito de la Seguridad Social la inclusión del servicio del hogar familiar en las normas de prevención y Seguridad Social tuvo lugar a lo largo de la década de los cuarenta (pese a que no se había asumido el carácter laboral de la relación jurídica), probablemente auspiciada por el contenido del Convenio núm. 24 OIT, de 8 de abril de 1932, relativo al seguro de enfermedad de los trabajadores de la industria, del comercio y del servicio doméstico que, como expresamente derivaba de su denominación, incluía en su campo de aplicación a los servidores domésticos. La materialización práctica de las previsiones al respecto, tras el fracasado intento de la Ley de 14 de diciembre de 1942, no tuvo lugar sino hasta la Ley de 19 de julio de 1944, que extendió al personal del servicio doméstico los beneficios de los subsidios y seguros sociales que disfrutaban los demás trabajadores, cuyo desarrollo se dilató en exceso ${ }^{10}$. En efecto, habría que esperar hasta la creación del llamado Montepío Nacional del Servicio Doméstico, por el Decreto 385/1959, de 17 de marzo de $1959^{11}$, para que se materializaran los primeros intentos por ofrecer un régimen de protección frente a los riesgos sociales ${ }^{12}$.

La protección dispensada por el Montepío respondió fielmente a la concepción histórica del servicio doméstico como trabajo sometido al amo, concibiéndolo como una "prolongación de la familia". Su regulación se destinaba a contribuir al perfeccionamiento de la moral y al progreso en todos los órdenes, concretamente, en el profesional del servidor. Como indica la doctrina, se trababa de una particular mezcla de dos concepciones: de un lado, basándose en el principio de igualdad y generalización, se aspiraba a un régimen de protección general; pero de otro, insertaba peculiaridades de tratamiento que ponían de manifiesto una visión paternalista de la relación. De la misma resultaba destacable la limitación subjetiva de su ámbito de aplicación, que para el sexo femenino quedaba reducida a las servidoras domésticas que fueran "solteras o viudas" si bien, tal limitación desaparecería poco después, aunque sometiéndola a determinados

\footnotetext{
${ }^{9}$ STSJ de Asturias, de 27 de septiembre de 2018 (RS núm. 1679/2018).

${ }^{10} \mathrm{El}$ artículo décimo facultaba al Ministerio de Trabajo para dictar cuantas disposiciones complementarias fueran necesarias para la ejecución de la Ley, desarrollo reglamentario que no se efectuaría hasta 1959.

${ }^{11}$ Cuya Exposición de Motivos empezaba indicando que "el ambiente cristiano de la sociedad española mantiene afortunadamente para el servicio doméstico su carácter tradicional como prolongación de la Familia. El aplicarle, sin circunsanciarlas a tal medio ambiente, las normas que en general se dictan para entidades de carácter laboral pudiera causar efectos contrarios a los laudables que se persiguen”.

${ }^{12}$ La primera propuesta de crear un Montepío fue en 1902, propuesta que no llegaría a materializarse, por lo que el aseguramiento de los riesgos sociales fue asumido por centros e instituciones religiosos, como el “Montepío de Previsión Social de la Divina Pastora”, en Quesada Segura, R., El contrato de servicio doméstico, op.cit., p. 218.
} 
requisitos ${ }^{13}$-, excluyendo también, a todo aquél en régimen de externos y que prestasen servicios a más de una casa.

Posteriormente, la reforma de la Seguridad Social llevada a cabo por la Ley de Bases de 1963, bajo los principios de unidad y homogeneidad, marcaría el desarrollo de su protección social distinguiéndose entre un régimen general y un conjunto de regímenes especiales, entre los que incluía a los servidores domésticos. En esta etapa, la inclusión de los servidores domésticos en el ámbito protector de los seguros sociales tuvo lugar gracias al "desarrollo de un sistema público de Seguridad Social superador de las limitaciones que la naturaleza de las distintas relaciones de trabajo imponían al régimen de seguros sociales” ${ }^{\text {14 }}$. Reiterada tal previsión en la Ley de Seguridad Social de 1966, se añadió la habilitación al Gobierno para que a través de normas reglamentarias regulase determinados regímenes especiales, entre los que se encontraba el de los servidores domésticos. Se daría cumplimiento al necesario desarrollo por el Decreto 2346/1969, de 25 de septiembre, por el que se regula el Régimen Especial de la Seguridad Social del Servicio Doméstico. El Decreto de 1969 tomará lo dispuesto en el Régimen General pero modulando intensamente la práctica totalidad de sus instituciones en base a una adaptación a las peculiaridades de la prestación de servicios aunque, como heredero del modelo proteccionista anterior, mantendría algunas de las especialidades preexistentes como la distinción entre dedicación exclusiva y permanente y, parcial o discontinuo-, pero ciertamente era revelador de un progreso que incidió decididamente en el ámbito subjetivo y en el alcance de la acción protectora. Esta regulación se mantendrá vigente, pese a su depuración constante, hasta la reforma llevada a cabo por la Ley 27/2011, de 1 de agosto, por la que debe entenderse tácitamente derogada ${ }^{15}$.

Tras la promulgación de la Constitución Española y, especialmente, tras la atribución del carácter laboral de la relación jurídica, surgieron con fuerza voces que reclamaban una profunda revisión de los postulados y contenidos del Decreto de 1969, cuyas disparidades, que podrían encontrar justificación en el contexto social en el que fue adoptado, esto es, en un marco proteccionista ciertamente masculinizado, perdía fuerza con los principios y valores que derivaban del Texto Fundamental y desde los postulados de la igualdad de género.

El contenido otorgado al RESS por el Decreto de 1969, junto con las condiciones laborales que posteriormente se reconocerían por el RD 1424/1985, de 1 de agosto, originaron una actividad laboral anclada en la informalidad, en la que la invisibilidad se instituyó como su principal seña de identidad, impidiendo que se disfrutase de la

\footnotetext{
${ }^{13}$ Con el Decreto 980/1960 de 19 de mayo de 1960 se ampliaría a las mujeres casadas cuyo marido se dedicase también al servicio doméstico, o se encontrase incapacitado de manera permanente o absoluta, o bien, estuviese separada de hecho o de derecho por causas no imputables a la misma.

${ }^{14}$ Luján Alcaraz, J., El Régimen Especial de la Seguridad Social de los Empleados de Hogar, Aranzadi, 2000, p. 21.

${ }^{15}$ Lo cierto es que la Disposición adicional trigésima novena de la Ley 27/2011, de 1 de agosto, no mencionaba expresamente el Decreto de 1969, es por ello que se consideró que se había llevado a cabo una derogación tácita respecto de todo aquello que se oponga a la Ley 27/2011, Miñarro Yanini, M., El trabajo al servicio del hogar familiar: análisis de su nueva regulación, Reus, 2013, p. 77.
} 
posición social propia de los trabajadores. Todo ello conectado e impulsado por una implícita y constante infravaloración de las tareas que se realizan en esta actividad, consideradas como genuinamente femeninas. El servicio al hogar familiar ha sido, y es, tanto por el lugar de prestación, como por el objeto y el sujeto de la relación, el ámbito por antonomasia que recrea más fielmente los roles de género más arcaicos, invisibilizando la importancia económica y política -función social- de todo lo relacionado con la esfera de la reproducción, es decir, con lo doméstico y el cuidado, y ello pese a realizar actividades que existen en el mercado productivo, las cuales sí tienen un mayor reconocimiento y por las que se paga un mayor precio ${ }^{16}$ que si por el contrario pasan a ser realizadas por la empleada de hogar.

La regulación de este actividad se encuentra bajo dos presiones: de un lado, las necesidades de las familias y, la atención que merece cuando se trata de regular una actividad que tiene como empleador al titular de un hogar familiar; y de otro, los derechos que como persona trabajadora le corresponde a quien desarrolla profesionalmente este trabajo.

Tanto la demanda como la oferta de empleo en el servicio al hogar familiar se encuentran caracterizadas por la intensidad que despliega en ellas la dimensión de género. En cuanto a la demanda, este tipo de trabajo está desarrollado mayoritariamente por mujeres y las funciones que realizan están marcadas por los roles de género. Es, además, frecuente en este tipo de trabajo, la presencia de mujeres extranjeras. La mayor incorporación de las mujeres españolas al mercado de trabajo originó un crecimiento en la demanda de servicios a fin de satisfacer las necesidades familiares no cubiertas por los hombres ni por políticas sociales. De otro lado, la oferta de empleo se genera por la misma cuestión de género, la necesidad de conciliar. Por esta razón, las reformas o avances que se lleven a cabo requieren de una profunda sensibilidad en materia de género: es necesario arbitrar los instrumentos para que esta actividad vaya eliminando su tendencia a desarrollarse en el marco del trabajo no declarado, pero sin aumentar de forma excesiva o inasumible su coste para las familias contratantes (esencialmente cuando la empleada de hogar satisface las necesidades de cuidados de familias trabajadoras).

La inclusión del servicio al hogar familiar en el sistema fue a costa de un Régimen Especial que implicó numerosas particularidades que generaron el anclaje de una infraprotección para las trabajadoras de esta actividad implícitamente justificada, precisamente, por su menor esfuerzo contributivo al sistema. No obstante, la alteración

\footnotetext{
${ }^{16}$ Es relevante hacer referencia a la diferencia existente entre precio y valor, ya que como destaca Pérez del Río, "se ha venido confundiendo siempre el precio del trabajo asignado a las mujeres y su valor en el mercado y ello sin duda ha tenido graves repercusiones de tipo social y económico. Las mujeres siempre han trabajado pero el trabajo que les ha sido tradicionalmente asignado, es decir, el trabajo reproductivo, ha sido siempre un trabajo sin precio en el mercado, es decir, no remunerado, y, como consecuencia, no se le ha asignado el menor valor económico", en "La valoración del trabajo de las mujeres: aspectos económicos y sociales”, Jornadas para la equiparación de condiciones en el mercado de trabajo: Igualdad de condiciones condición de igualdad, AGORA, Institut Catalá de la Dona, Generalitat de Catalunya. Barcelona, 2002.
} 
de algunos de sus elementos, que potenciaban precisamente tal desigualdad, se revelaron carentes de razonabilidad, excesivos desde la justificación de la especialidad, por lo que, dada su existencia desde 1969, sin que fuesen sometidos a una revisión profunda sobre la motivación de la existencia de cada una de ellos, unido a los cambios legales y sociales experimentados, llevó a cuestionar sobre su difícil justificación desde el principio de igualdad y no discriminación por razón de género.

Precisamente la exigua contribución al sostenimiento del sistema se ha tomado para justificar una protección caracterizada por su contenido deficitario. Siendo esto último, precisamente, una de las razones más importantes que ha impulsado la nueva regulación, situada en un contexto en el que prima los principios de contributividad y adecuación. Y es que la relación afiliado-pensionista ha sido en este Régimen Especial muy baja: el servicio al hogar familiar se ha caracterizado por el acceso a unas pensiones de cuantías bajas, que ha significado un acceso masivo a los complementos por mínimos. Tal preocupación lleva al legislador a tratar de impulsar un aumento del número de cotizantes -y con ello, el afloramiento del trabajo no declarado, especialmente, el de carácter parcial-, y de la cuota de cotización -con claros fines recaudatorios-. Y llega a ser tan esencial el alcance de tal objetivo, directamente vinculado a la contributividad que inspira al sistema, que eclipsa a otros de igual importancia. De manera que, pese a la pugna en la defensa de los derechos sociales y fundamentales, los mismos quedan finalmente mermados cuando amenazan la consecución de la sostenibilidad del sistema.

Tales preocupaciones vinieron a postergar durante más de cuatro décadas una actuación decidida en el servicio doméstico. Y es que, si bien, desde el Pacto de Toledo de 1995 se instituyó la necesaria simplificación e integración de los Regímenes Especiales en el General -buscándose la tendencia a la unidad de la estructura del sistema de la Seguridad Social a través de la Recomendación Tercera (homogeneización financiera) y la Recomendación Sexta (integración de los regímenes)-, las posteriores modificaciones han ido eludiendo una actuación en tal sentido. Sería el Acuerdo para el crecimiento, el empleo y la garantía de las pensiones del año 2011, con el que finalmente se materializaría el proceso de integración, que tuvo lugar con la disposición adicional trigésima novena de la Ley 27/2011, de 1 de agosto, mediante la creación de un Sistema Especial en los términos y alcance precisados en tal disposición “y con las demás particularidades que se determinen reglamentariamente”; cuyo apartado quinto habilitaría al Gobierno para proceder a modificar la relación laboral especial, que se llevó a cabo con el RD 1620/2011, de 14 de noviembre ${ }^{17}$. El contenido de la disposición adicional trigésima novena se introdujo, con el Real Decreto Legislativo 8/2015, de 30 de octubre, en el Texto Refundido de la Ley General de la Seguridad Social, en la sección primera del capítulo XVIII, del Título II, denominada "Sistema especial para empleados de hogar". No obstante, no puede desconocerse que este proceso de mejora

\footnotetext{
17 Real Decreto 1620/2011, de 14 de noviembre, por el que se regula la relación laboral de carácter especial del servicio del hogar familiar.
} 
en lo que respecta a la protección social se inició un poco antes. En efecto, la Ley 39/2010, de 22 de diciembre, de Presupuestos Generales del Estado para el año 2011, en la disposición final tercera, apartado nueve, se añadía una nueva disposición adicional, la quincuagésima tercera, a la LGSS de 1994, reconociendo al servicio del hogar familiar el acceso a las contingencias profesionales que, hasta entonces, había estado privado de esta protección. Con tal actuación se fortalecía el carácter laboral de la relación, y los primeros intentos por iniciar el proceso de equiparación. Tendría lugar entonces la aprobación del Real Decreto 1596/2011, de 4 de noviembre, por el que se desarrolló la disposición adicional quincuagésima tercera de la LGSS de 1994, en relación con la extensión de la acción protectora por contingencias profesionales a los trabajadores incluidos en el Régimen Especial de la Seguridad Social de los Empleados de Hogar.

Este proceso de mejora del contexto normativo del servicio al hogar familiar español no ha sido aislado, por el contrario en el mismo ha influido la actuación de la OIT, especialmente, por los trabajos realizados y plasmados en 2011 con la adaptación del Convenio núm. 189 sobre trabajadoras y trabajadores domésticos, y la Recomendación núm. 201 sobre el trabajo decente para las trabajadoras y los trabajadores domésticos que lo complementa. Estos documentos han sido considerados "como un hecho histórico, como una conquista social”, pero sin que ello haya impedido la crítica por la presencia limitada de la perspectiva de género en su redacción, reprochándose igualmente la utilización en su articulado de la referencia al "trabajador doméstico", que impide visualizar la realidad a la que precisamente se dirige, a "las auténticas protagonistas de este trabajo" 18 . Por lo que respecta a la Seguridad Social, se dirige un mandato a los Estados a fin de que garanticen "condiciones no menos favorables que las condiciones aplicables a los trabajadores en general con respecto a la protección de la seguridad social, inclusive lo relativo a la maternidad" ${ }^{19}$. Este Convenio no ha sido ratificado por España, pese a que desde instancias comunitarias se promueve su adhesión “con el fin de reforzar los derechos de los trabajadores domésticos y asistenciales europeos”20.

Desde el Parlamento Europeo se ha insistido que "el trabajo doméstico y los cuidados deben ser una profesión libremente elegida, que garantice a los trabajadores un amparo adecuado y humano en términos de derechos, protección, dignidad de vida y

\footnotetext{
${ }^{18}$ Quesada Segura, R., “La dignificación del trabajo doméstico. El Convenio núm. 189 OIT, 2011”, Revista General de Derecho del trabajo y de la Seguridad Social, núm. 27, 2011, p. 6.

${ }^{19}$ La doctrina ha matizado que el Convenio núm. 189 "no habla de equiparación, sino, en redacción complicada, de "condiciones no menos favorables" que las condiciones aplicables a los trabajadores en general. De todo lo cual puede deducirse que, en un régimen singular se podrán establecer condiciones o excepciones respecto al régimen general de seguridad social, pero que, cuando se contemple un régimen de protección especifico, este no puede tener un tratamiento in peius respecto al régimen común”, Quesada Segura, R., “La dignificación del trabajo doméstico...”, op.cit., , pp. 28-29.

${ }^{20}$ En el Informe "sobre las trabajadoras domésticas y las cuidadoras en la UE" (2014/2094(INI)), de 5 de abril de 2016, el Parlamento Europeo "anima a todos los Estados miembros a que ratifiquen con urgencia el Convenio n 189 de la OIT”, p. 16.
} 
perspectivas de desarrollo personal”21. Entre sus propuestas debemos destacar la solicitud a la Comisión para que elabore un conjunto de instrumentos políticos, tanto legislativos como no legislativos, que introduzcan un marco general para la profesionalización del trabajo, a fin de que se reconozcan y normalicen las profesiones y competencias, y la consolidación de las carreras; y proponga con urgencia una Directiva dirigida, entre otros objetivos, al establecimiento de unas normas mínimas y comunes de protección social. Considera que el reconocimiento de este sector profesional reduciría el trabajo no declarado, mejorando la calidad de vida de las personas que lo desempeñan, lo que "les ofrece prestaciones sociales y protección contra los abusos y la discriminación, y disminuye el riesgo de pobreza, marginación, estigmatización y desprestigio para quienes lo realizan, al tiempo que proporciona mayores garantías de calidad en el servicio al empleador y contribuye a incrementar la recaudación para el fondo de la seguridad social de los Estados". En definitiva, se observa un fortalecimiento de la actuación comunitaria sobre el trabajo doméstico, quizás auspiciada por la propia del OIT, pero que en todo caso implica un nuevo paso hacia la valoración de esta actividad y la exigencia de que los Estados adquieran compromisos.

Han sido las demandas sociales y doctrinales las que han visibilizado la necesidad de una mayor equiparación desde la óptica de género. Sin embargo, debemos asumir que el motivo esencial que ha forzado la actuación del legislador fue precisamente el fin hacia la homogeneidad del sistema, junto con la búsqueda de nuevas vías de contribución; y junto a todo lo anterior, igualmente, hacer emerger un colectivo para lograr incrementar el número de ocupados, en un contexto laboral ciertamente alarmante.

Proceso de racionalización interna que se ha desarrollado a través de la revalorización de la técnica organizativa instrumental de los Sistemas Especiales, reveladora de una de las líneas de tendencia de las reformas en Seguridad Social, considerada por algunos como necesaria para cumplir con el fin hacia la homogeneización y simplificación, pero que en definitiva ha permitido mantener un amplio margen de flexibilidad en su configuración.

El artículo 11 LGSS establece que "en aquellos regímenes de la Seguridad Social en que así resulte necesario, podrán establecerse sistemas especiales exclusivamente en alguna o algunas de las siguientes materias: encuadramiento, afiliación, forma de cotización o recaudación. En la regulación de tales sistemas informará el ministerio competente por razón de la actividad o condición de las personas en ellos incluidos”. Como tendremos ocasión de incidir, en la configuración del Sistema Especial de empleadas del hogar se ha desdibujado el alcance de lo permitido legalmente por tal instrumento y de su propia conceptualización en oposición a los Regímenes Especiales, precisamente porque se han mantenido particularidades en la acción protectora sin tener en cuenta que la habilitación de la especialidad se reducía exclusivamente a alguna o algunas de las determinadas y concretas materias citadas entre las que no se incluye la

${ }^{21}$ PARLAMENTO EUROPEO, Informe “sobre las trabajadoras domésticas y las cuidadoras en la UE” (2014/2094(INI)), de 5 de abril de 2016, p.29. 
acción protectora. Esto ha llevado a detectar "una parcial desnaturalización de la noción de sistema especial” 22 , y a cuestionar si la misma caracteriza finalmente a un proceso de integración meramente formal, subrayándose que "no se ha procedido a sustituir el Régimen Especial, sino a modificar el régimen jurídico y variar su ubicación dentro de la estructura del sistema [...], la pretensión de simplificar y racionalizar la estructura del sistema [...] requiere la homogeneización de la acción protectora”23.

Nos centraremos en las particularidades más relevantes de este Sistema Especial para determinar si las mismas se encuentran justificadas en la especialidad que ahora se permite desde este marco legal. Nos interesará destacar aquellos avances producidos respecto de la regulación precedente, es decir, si los mismos son suficientes o no para superar las desigualdades detectadas, y aquellos otros aspectos que se mantienen intactos.

\section{3.- EL ACCESO AL SISTEMA ESPECIAL: EL RÉGIMEN DE ENCUADRAMIENTO Y COTIZACIÓN}

La incorporación de las empleadas de hogar en el Régimen General supuso la mutación de dos de los elementos que presentaban una mayor desigualdad, y en los que se residenciaba, en términos jurídicos, la principal causa por la que en esta actividad existe una grave tendencia hacia el trabajo no declarado: el régimen de encuadramiento y de cotización en función de la modalidad de la prestación de servicios.

La integración en el RGSS supondría la superación de una de la principales especialidades en protección social de esta relación laboral especial -salvo por el régimen transitorio que introdujo-, coherente con su condición de trabajadora por cuenta ajena, consistente en la atribución de la responsabilidad del cumplimiento de las obligaciones de afiliación, alta y cotización al titular del hogar familiar, independientemente del régimen de prestación de servicios, esto es, al margen de si la empleada lo fuera a tiempo completo o parcial, y/o prestara sus servicios para uno o varios empleadores. Ello implicó la obligatoriedad del acceso al sistema de un elevado número de empleadas que desempeñaban su actividad a tiempo parcial, y que hasta ese momento la norma abocaba a la informalidad en base a un criterio de marginalidad. Se superaba entonces una regulación cuya configuración se dirigía implícitamente, pero real en la práctica cotidiana, a un determinado perfil de empleadas, aquellas que trabajaban de manera exclusiva y permanente para un solo empleador, de modo que si no lo eran, las dificultades para incorporarse a la Seguridad Social las condenaban a una expulsión de su acción protectora presente y futura. Cuestión que no es baladí teniendo

\footnotetext{
${ }^{22}$ Vicente Palacio, A., "La simplificación de la estructura del sistema de Seguridad Social. El final diferido de un extenuante maratón todavía inacabado”, Economía Española y Protección Social, núm. 4, 2012, p.135.

23 Rodríguez Cardo, I.A., "El nuevo sistema especial de empleados de hogar: una «revolución» inconclusa”, Revista Española de Derecho del Trabajo, núm. 158, 2013, p. 149-152. Concluyendo que, con la integración de los trabajadores agrícolas y de los empleados de hogar, se han creado "auténticos regímenes especiales dentro de otro régimen del sistema de Seguridad Social”.
} 
en cuenta que el número medio de horas habitualmente trabajadas es sensiblemente inferior a una jornada completa ${ }^{24}$.

Tales dificultades derivaban del carácter marginal que la norma otorgaba a la prestación de servicios cuando no superaba un determinado límite temporal, atribuyendo, en tal caso, las responsabilidades de afiliación, alta y cotización a las propias empleadas, situándolas en una posición cercana a la de los trabajadores autónomos ${ }^{25}$. Ello implicaba la asunción de una cuota que resultaba excesiva si tenemos en cuenta la fórmula de su determinación en la anterior regulación -de la que se dará cuenta posteriormente-, especialmente para las trabajadoras parciales, y los bajos salarios que caracterizan a esta relación laboral. Ante esta encrucijada se hizo patente que las empleadas de hogar optaban por mantenerse en la informalidad, ya que era más rentable disponer de un mayor ingreso económico para su propio hogar que asumir una cotización que, atendiendo al desarrollo de su carrera profesional y a la formulación jurídica de la acción protectora, no se perfilaba como posible generadora de una prestación, ni de carácter inmediato, como pudiese ser frente a la contingencia de desempleo -en este caso debemos hablar de imposibilidad absoluta-, ni más lejana, como la protección de la vejez o la incapacidad.

Es importante detenernos en este aspecto, pues entra en conexión con la reforma introducida por el RD-Ley 29/2012, de 28 de diciembre ${ }^{26}$, como veremos seguidamente. Al efecto, el artículo 6 del Decreto de 1969 diferenciaba entre aquellos servicios prestados "de manera exclusiva y permanente", en cuyo caso recae sobre el empleador la carga de afiliación, alta y cotización, y aquellos otros de "carácter parcial o discontinuo, a uno o más cabezas de familia”, en el que la empleada era responsable de tales obligaciones.

Dos cuestiones se planteaban en relación con este tratamiento diferenciador. De un lado, el debate en torno a su justificación, que no se hallaba en la especialidad de la relación laboral sino que, de nuevo, eran otras las motivaciones que habían llevado a tal regulación, -vinculadas a facilitar una descarga del peso burocrático que en caso contrario debían de soportar los empleadores-, las cuales resultaban superadas desde hacía bastante tiempo. Una de las razones de tal superación se encontraba en la regulación que introdujo el Estatuto de los Trabajadores en relación con el trabajo a

24

\begin{tabular}{|c|c|c|c|c|c|c|}
\cline { 2 - 6 } & \multicolumn{6}{c|}{ Horas medias semanales trabajadas por ocupado } \\
\cline { 2 - 6 } & \multicolumn{2}{|c|}{ HORAS EFECTIVAMENTE TRABAJADAS } & \multicolumn{2}{c|}{$\begin{array}{c}\text { HORAS HABITUALMENTE } \\
\text { TRABAJADAS } \\
\text { Todos los ocupados }\end{array}$} & $\begin{array}{c}\text { Ocupados que han trabajado } \\
\text { en la semana de referencia }\end{array}$ & \multicolumn{2}{c|}{$\mathbf{2 0 1 7}$} & \\
\cline { 2 - 6 } & $\mathbf{2 0 1 6}$ & $\mathbf{2 0 1 7}$ & $\mathbf{2 0 1 6}$ & & \\
\hline $\begin{array}{c}\text { T Aciv. Hogares } \\
\text { empleadores personal } \\
\text { doméstico, } \\
\text { productores bienes y } \\
\text { serv }\end{array}$ & 25,1 & 24,8 & 26,4 & 26,2 & 27,0 & 26,9 \\
\hline
\end{tabular}

Fuente: Encuesta de Población Activa

${ }^{25}$ Como una especie de “autónomos impropios” los denomina López Gandía en., "La convergencia entre regímenes de Seguridad Social”, Temas Laborales, núm. 81, 2005, p. 219.

${ }^{26}$ Real Decreto-ley 29/2012, de 28 de diciembre, de mejora de gestión y protección social en el Sistema Especial para Empleados de Hogar y otras medidas de carácter económico y social. 
tiempo parcial, lo que ciertamente conecta con la segunda cuestión, esta es, la determinación de lo que se debía entender por prestación de servicios a tiempo parcial. Para tal concreción se acogería lo dispuesto en la Resolución de la Dirección General de la Seguridad de 9 de septiembre de 1971, que excluía a las empleadas de hogar que prestasen servicios durante menos de setenta y dos horas mensuales distribuidas en menos de doce jornadas. Los tribunales entendieron que tal Resolución complementaba al Decreto de 1969, por lo que se consagraría la exclusión del trabajo marginal. Sin embargo, lo anterior no se asumió pacíficamente por toda la doctrina judicial ${ }^{27}$ dado que, en defensa del principio de jerarquía normativa, atribuirían a tal Resolución un mero valor interpretativo, sin que la misma pudiese validar la remisión efectuada por el artículo 49.1.2 del RD 84/1996, de 26 de enero -que disponía que "se considerarán servicios a tiempo parcial los que se presten durante un tiempo inferior a ochenta horas de trabajo efectivo durante el mes, siempre que superen el mínimo que establezca al respecto el Ministerio de Trabajo y Seguridad Social” - al reglamento, a fin de establecer el mínimo de horas de trabajo efectivo mensual que determina la inclusión o no en el sistema de Seguridad Social. No obstante, pese a la dificultad de su admisión, este ha sido el criterio que siguió la práctica administrativa. Esto último, pese a que tras la reforma del artículo 12 ET propiciada por el RD-L 15/1988, de 27 de noviembre, existía un criterio concreto que delimita el trabajo a tiempo completo y el trabajo a tiempo parcial, considerando a éste último como aquel en el que se "preste servicios durante un número de horas al día, a la semana, al mes o al año, inferior al considerado habitual en la actividad de que se trate en dichos períodos de tiempo". Es por ello que se demandaba desde entonces una reforma que equiparase lo dispuesto en el RD 84/1996, de 26 de enero, a la definición de trabajo a tiempo parcial. Modificación que llegaría con la Ley 27/2011, de 1 de agosto, por la cual, el único responsable de las obligaciones de afiliación, alta y cotización, sería el titular del hogar familiar.

Sin embargo, esta mayor nivelación no pudo afrontarse sin aumentar de manera sustancial las cargas económicas, administrativas y de gestión para la parte empleadora, lo cual, siendo inevitable, debió guiar el proceso hacia la integración, es decir, el perfil genuino de los empleadores y la causa que motivaba la contratación de estos servicios, exigía que tales motivaciones estuvieran presentes como el principal foco generador del avance material y no meramente formal de la igualdad, al que debió de dirigirse, sin titubeos, la actuación legislativa sobre esta actividad ${ }^{28}$. Los resultados del balance

\footnotetext{
${ }^{27}$ La STSJ Comunidad Valenciana 17 de junio de 1992 (RS núm. 430/1991), se pronunció en los siguientes términos: "el art. 9.3 de la Constitución Española garantiza el principio de jerarquía normativa, así como la publicidad de las normas, y en los presentes autos, la pretendida norma, jerárquicamente inferior, cual es la resolución, no puede excluir o limitar un derecho reconocido en la norma superior, cual es el de ser encuadrada y afiliada en el meritado régimen especial, sin que pueda aceptarse tampoco lo dicho sobre interpretación auténtica, pues una cosa es interpretar y otra muy distinta modificar la norma que se dice interpretada, máxime cuando tal resolución, ni siquiera es una norma publicada, cual exige el art. 9.3 de la Constitución Española, sino tan sólo una norma interna”.

${ }^{28}$ Concretamente la obligación de notificar los cambios de retribución en el mes que se produzcan originó un elevado número de quejas y consultas. De ello fue informada la TGSS por escrito presentado por la Secretaria de Estado, a lo cual respondió que pese a que se realiza las acciones necesarias para facilitar el
} 
presentado a menos de cumplirse un año de la entrada en vigor puso de manifiesto anomalías en su funcionamiento que motivaron la urgencia de introducir mejoras en su configuración jurídica, siendo por tanto "el funcionamiento parcialmente anómalo del sistema especial lo que determinaría su modificación”29. Pero aunque pudiese pensarse que la preocupación se centraba en esa mayor carga burocrática del empleador, lo cierto es que en tal intervalo no se produjo un descenso del número de empleadas de hogar en el sistema de Seguridad Social. Se trataba por ello de analizar la efectividad, la eficacia y la eficiencia de la norma. Realmente el afán reformista no hacía sino revelar, no lo inadecuado de la norma en relación con esta materia, sino el insuficiente apoyo económico con el que contó su aplicación. Lo que sí se destacaba era un descenso en la recaudación que se esperaba conseguir, lo que pudo deberse a múltiples y complementarios factores, entre ellos, la reducción de la remuneración recibida por la empleada (en el peor de los casos, pero más probable, una disminución real, reveladora de que el coste social que implica la cotización quedaba repercutido sobre la empleada,), o la aplicación de las bonificaciones otorgadas ${ }^{30}$.

Con tales premisas, el RD-Ley 29/2012, de 28 de diciembre, vino a (re)instaurar un tratamiento diferenciador en función de la modalidad de la prestación de servicios que, si bien, no retornaba a la situación creada por el Decreto de 1969, sí originó una especie de "déjà vu” de aquello que tanto tiempo había costado superar. De forma que cuando se trate de una prestación de servicios de menos de 60 horas mensuales por empleador, la empleada deberá formular directamente su afiliación, y será responsable de las altas, bajas y variaciones de datos, así como, de la asunción de la obligación de cotizar, "cuando así lo acuerden con sus empleadores"; si bien, aun cuando la empleada asuma tales responsabilidades "el empleador estará obligado a entregar al trabajador, además del recibo de salarios en todo caso, la aportación y cuota que, por los días del mes en que hubiera estado a su servicio, le corresponda por las contingencias comunes y profesionales”. La exposición de motivos del RD-L 29/2012, de 28 de diciembre, explica que con ello se logrará "agilizar y facilitar la realización de tales actuaciones cuando las tareas domésticas se realicen durante un escaso número de horas”, favoreciendo obviamente a este tipo de empleador, justificando tales modulaciones "en la consideración como una situación singular merecedora de una regulación específica”.

cumplimiento, la comunicación por parte del empleador era el único medio por el que se podía conocer ese dato, imprescindible a efectos de cotización. "Informe sobre el balance de la integración de los trabajadores del Régimen Especial de Empleados del Hogar en el Sistema Especial para empleados de hogar en el Régimen General”, Secretaria de Estado de Seguridad social, septiembre 2012. p. 32.

29 Gala Durán, C., "La protección en materia de seguridad social de los empleados de hogar tras el RDL 29/2012: un viaje de ida y vuelta”, Relaciones laborales y empleados del hogar: reflexiones jurídicas, Espuny Tomás, M.J y, García González, G., Dykinson, 2014, p.148.

30 Durante el periodo transitorio la recaudación disminuyó en 12,59 millones de euros, un -3,95 por ciento. La razón se encontraba en el disfrute de las bonificaciones, y en el efecto que suponía cotizar por una base cercana a los salarios y no en base a una fija, apreciándose un descenso en la cuantía pues la base de cotización media era inferior a 748,20 euros/mes. De esta forma, se precisaba en el "Informe sobre el balance de la integración de los trabajadores del Régimen Especial de Empleados del Hogar en el Sistema Especial para empleados de hogar en el Régimen General”, op.cit., pp.41 y ss. 
Con esta reforma se originó un régimen del que sería posible diferenciar hasta cuatro tipos de empleadas: (1) la empleada a tiempo completo; (2) la empleada a tiempo parcial que presta sus servicios durante un tiempo inferior a 60 horas mensuales por hogar familiar, pudiendo trabajar para uno o para varios empleadores, pero siempre por debajo de las 60 horas al mes; (3) la empleada a tiempo parcial que presta sus servicios para uno o varios empleadores pero alcanzando en cada uno de ellos las 60 o más horas mensuales; (4) y aquellas otras también a tiempo parcial pero que trabaja 60 o más horas mensuales en uno o varios hogares familiares, y menos horas en otros. De estas posibilidades, la regulación introducida por el RD-Ley 29/2012, de 28 de diciembre, incide en los supuestos segundo y cuarto mencionados -en este último, respecto de aquellos empleadores en los que no se alcancen las 60 horas, originándose ciertamente una situación híbrida o mixta, que la doctrina califica como un supuesto de “pluriempleo con especialidades”31-, pues el límite de 60 horas debe entenderse referido respecto de cada uno de los empleadores.

Se ha considerado que "las peculiaridades de este colectivo y la dificultad de control son motivos más que suficientes" para establecer, "mediante norma reglamentaria, un mínimo de horas para entender comprendidos a los empleados del hogar en el campo de aplicación del SEEH” ${ }^{32}$, o incluso, se ha defendido la posibilidad de suprimir la obligación de alta en situaciones de trabajo domésticos marginal "-o quizás incluso no estrictamente marginal-, atribuyendo al trabajador la facultad de decidir si quiere o no incorporarse al Sistema [...] aspirar al respeto general de la obligación de alta y/o afiliación parece utópico, y si la sanción por el incumplimiento presenta graves inconvenientes, la voluntariedad en el acceso al Sistema, a través de la suscripción de un convenio especial, permite conciliar mejor los diferente intereses en juego" 33 . Mostramos nuestro rechazo a tales planteamientos, pues consideramos que tal defensa no es más que una injustificada vía de escape contraria a la laboralidad por cuenta ajena de esta relación jurídica, e insistimos, al principio de igualdad de género, pues ello implicaría no solo la negación del estatus de trabajadora, sino de su protección social. La defensa de la expulsión de los llamados empleos menores o marginales no es una cuestión ajena a la igualdad de género, dado el impacto que la misma genera. No obstante, en esta búsqueda de soluciones que satisfagan los intereses de ambas partes implicadas, quizás hubiese sido aconsejable al legislador ampliar su visión, planteando otras alternativas de contratación a través de empresas que ofrezcan estos servicios o intermedien en ellos. En España tal tejido no adquiere fortaleza dado el encarecimiento de los costes y los escasos márgenes de beneficios ante la carencia de medidas que favorezcan este recurso por las personas que necesiten de tales servicios (se debe abonar el IVA, dado que la empresa tiene la obligación de emitir factura); y por la intensa desconfianza que muestran las asociaciones del sector hacia estas empresas,

\footnotetext{
${ }^{31}$ Gala Durán, C., “La protección en materia de seguridad social de los empleados de hogar...”, op.cit., p. 155.

${ }^{32}$ Martínez Lucas, J.A., "La afiliación, altas, bajas y cotización en el Sistema Especial de Seguridad Social para Empleados de Hogar”, Actualidad Laboral, núm. 13-14, 2012, p. 2466.

${ }^{33}$ Rodríguez Cardo, I.A., "El nuevo sistema especial de empleados de hogar...”, op.cit., p. 196.
} 
subrayándose en reiteradas ocasiones el incumplimiento de los derechos laborales ${ }^{34}$. Sin retroceder en lo avanzado, la apuesta decidida por la existencia de empresas de servicios, que buscasen una rentabilidad mínima, y destinadas a facilitar a los empleadores el cumplimiento de los requisitos formales exigidos legalmente, ayudaría a avanzar en la profesionalización y regularización de este empleo. Esta vía ayudaría a la gestión, especialmente, de aquellas familias que requieren de servicios durante un tiempo determinado. Se trata de ofrecer una doble posibilidad, a fin de que se acuda a aquella que le resulte más conveniente, sin que la decisión se encuentre condicionada a la mayor onerosidad del servicio. Es por ello que, como decimos, se tratarían de empresas cuyos márgenes de beneficios serían muy limitados, en las que deben primar la búsqueda de la satisfacción de las necesidades de la sociedad, que cuenten con un exquisito apoyo institucional, y con un exhaustivo control que permita superar el carácter fraudulento y explotador con el que en la actualidad se identifica y caracteriza esta actividad.

Cabe indicar que en todo lo relativo a la asunción de responsabilidades de encuadramiento y cotización, tanto en el anterior régimen, como en el creado en 2011, alterado finalmente en 2012, es esencial tener presente que un elevado porcentaje de empleadas afiliadas y dadas de alta, tanto con anterioridad a la reforma, como posterior a ella, viene constituido por mujeres extranjeras. Teniendo presente la elevada informalidad que ha caracterizado a esta actividad ${ }^{35}$, lo cierto es que acudiendo a los datos disponibles, éstos reflejaban una afiliación y alta de personas extranjeras próximo al 60 por ciento respecto del total a finales del 2011.

El motivo se encuentra en los requisitos exigidos para proceder a la renovación de las pertinentes autorizaciones de residencia y trabajo que permiten disfrutar de una situación administrativa regular. Esto supone que la formalización del contrato y consiguiente incorporación al sistema de Seguridad Social se convierte para las mujeres extranjeras en un elemento imprescindible, pues el cumplimiento de los mismos será determinante de su situación administrativa en España. De lo contrario las trabajadoras inmigrantes experimentan lo que se conoce como irregularidad sobrevenida, ante la imposibilidad de conseguir las renovaciones pertinentes ${ }^{36}$. Esta experiencia hace más vulnerable, si cabe, a la mujer inmigrante. Es fácil deducir, en el contexto de la anterior regulación, que la exigencia de tales requisitos administrativos era el motivo principal de la mayor presencia de mujeres extranjeras en los datos de afiliación y alta en Seguridad Social, pues para las nacionales escasos incentivos tenía su formalización,

\footnotetext{
${ }^{34}$ Muestra esta preocupación la Asociación de Trabajadoras de Hogar de Bizkaia que ha procedido a denunciar en reiteradas ocasiones ante la Inspección de Trabajo a agencias de colocación por las condiciones abusivas a las que sometían a sus trabajadoras: http://www.ath-ele.com/.

35 "Los déficits en la cobertura de la seguridad social del trabajo doméstico también afectan a los países industrializados; por ejemplo, en Italia casi el 60 por ciento del personal de trabajo doméstico no está afiliado ni contribuye a los sistemas de seguridad social. En España y Francia, la exclusión alcanza a cerca del 30 por ciento del trabajo doméstico". OIT, "Protección social del trabajo doméstico. Tendencias y estadísticas”, documento 16, 2016, p. 11.

${ }^{36}$ Se ha seguido a Vela Díaz, R., Empleo, trabajo y protección social de las mujeres extranjeras en España. Un enfoque de género de la política migratoria, Comares, 2014, pp. 24-33.
} 
especialmente, si tenemos en cuenta que para éstas es más frecuente la prestación de servicios parcial o discontinua.

En definitiva, la anterior regulación existente hacía factible a las empleadas extranjeras el sostenimiento, bajo su propia actuación, de la legalización de su situación administrativa, asumiendo para lograrlo las cargas sociales necesarias, lo que hacía aún más marginal el desarrollo de esta actividad. La transformación que supuso la integración operada por la Ley 27/2011, de 1 de agosto, no tuvo en cuenta este impacto, es decir, se ignoró las repercusiones que la traslación de las responsabilidades de encuadramiento y cotización al empleador, como condición sine qua non, supondría para las empleadas extranjeras. La mutación del régimen establecido con la llegada del RD-L 29/2012, 28 de diciembre, crearía una nueva vía para el encauzamiento de tales situaciones, aunque dudamos que tales razones constituyesen el impulso que llevó al legislador a abordarla, al menos, no expresamente.

En todo caso, la evolución del número de afiliaciones y altas muestra que el afloramiento que se ha logrado ha incidido de manera más notable en las nacionales que en las extranjeras, lo que puede deberse a diversas razones: como dijimos anteriormente, en las nacionales la tendencia a mantenerse en un contexto de trabajo no declarado era mayor y con el avance de derechos es más atractivo luchar por salir del nicho en el que se encuentran; o bien que, sencillamente, haya aumentado la presencia de mujeres autóctonas en este sector de actividad, lo que puede deberse a la necesidad de empleo motivada por la crisis económica; y consecuente con esto último, la correlativa disminución de extranjeras a causa de la recesión en la concesión de autorizaciones de residencia y trabajo ${ }^{37}$.

En la búsqueda de una mayor efectividad de la norma quizás hubiese sido más adecuado la puesta en práctica de otras alternativas: así, en los supuestos de prestación de servicios para personas mayores o discapacitadas, considerar como empleador a los familiares (hijos, hermanos, etc), que ejerzan el poder de organización de los trabajos y demás vicisitudes de la relación, pese a que no vivan con aquellos, sin que ello tenga la consideración de cesión ilegal de trabajadores; en este mismo supuesto, si no se existieran familiares que se puedan hacer cargo de tales responsabilidades, proceder a la creación de una figura pública que sustituyera al empleador en la tramitación de todas sus obligaciones.

Por lo que respecta a la otra modificación que llevaría a cabo el RD-Ley 29/2012, de 28 de diciembre, la misma tuvo lugar en los aspectos cotizatorios, alterando la forma en

37

\begin{tabular}{|c|c|c|}
\hline \multicolumn{2}{|c|}{ Trabajadores afiliados a la Seguridad Social (total y extranjeros) } \\
\hline $\begin{array}{c}\text { Afiliación. } \\
\text { Trabajadores afiliados en alta } \\
\text { laboral }\end{array}$ & $\mathbf{2 0 1 6}$ & 429,1 \\
\cline { 2 - 3 } & $\mathbf{2 0 1 7}$ & 424,4 \\
\hline $\begin{array}{c}\text { Afiliación. } \\
\text { Trabajodores extranjeros } \\
\text { afiliados a la } \\
\text { Seguridad Social }\end{array}$ & $\mathbf{2 0 1 6}$ & 195.893 \\
\cline { 2 - 3 } & $\mathbf{2 0 1 7}$ & 184.475 \\
\hline
\end{tabular}

Fuente: MITRAMISS 
que tal adaptación iba a llevarse a cabo de acuerdo con lo establecido, por entonces, en la DA 39a de la Ley 27/2011, de 1 de agosto.

Como ya hemos señalado, el menor esfuerzo cotizatorio que caracterizaba a esta actividad se erigió en uno de los elementos más relevantes a abordar en la nueva regulación, pues era imperativo equiparar la técnica de cálculo de la cuota utilizada con la prevista en el Régimen General, a fin de encontrar "un equilibrio entre la protección adecuada y la contribución suficiente” ${ }^{38}$. Carácter deficitario que derivaba de un modelo de cotización que estaba desconectado de los salarios percibidos. Con anterioridad a la reforma del 2011, la cotización se basaba en el ingreso de una cuota "única, mensual e indivisible” -artículo 15.1.a) del Decreto de 1969-, que se mantenía en unos límites bajos -su importe se fijaba por el Gobierno "en función del número de empleados de hogar protegidos y el coste global de la acción protectora”-, lo que respondía a los objetivos de no encarecer las cargas sociales del empleador, pero también para evitar el empleo sumergido no haciendo compleja e inasumible la cuota cuando es la empleada quien deba hacerse cargo de ella. Sin embargo, la necesidad de mantener tales cuotas fijas originó que numerosas personas se dieran de alta sin ser verdaderamente empleadas de hogar, con la intención de acceder fraudulentamente a los beneficios de la Seguridad Social. No obstante, posteriormente, el Decreto 825/1976, de 22 de abril, por el que se regula la cotización en el Régimen Especial de la Seguridad Social de los Empleados de Hogar, vino a mitigar tal desajuste derivado: de un lado, de la forma de fijación de la base de cotización y de la invariabilidad con la que se había mantenido la cuantía pese a la previsión de que la misma fuera modificada en función del salario mínimo interprofesional; y, de otro, de la previsión del artículo 25 del Decreto de 1969 consistente en que la base de cotización a utilizar a fin de calcular las prestaciones económicas sería la tarifa mínima de cotización que para los trabajadores mayores de dieciocho años hubiera estado vigente en cada momento en el RGSS. A tal fin se modificó la base de cotización para equiparla al tope mínimo de las bases de cotización que se encontrasen vigentes en cada momento en el Régimen General, aplicando un tipo de cotización que se fijaría en el 10 por ciento. Finalmente, desde 1989, con el RD 24/1989, de 13 de enero ${ }^{39}$, se estableció un tipo invariable que se situaba en el 22 por ciento, el cual, mantendría su vigencia, hasta la reforma del 2011.

Esta opción por una cuota tarifada con independencia de la modalidad de prestación de servicios, de sus salarios, o de su cualificación, se convirtió en el principal impulso hacia la informalidad, de su "autoexclusión" 40 del REEH, especialmente, de aquellas trabajadoras que debían de hacerse cargo del pago de la cuota, precisamente cuando por ser su jornada reducida su retribución hacía imposible o de difícil cumplimiento tal obligación. A ello debemos añadir que las empleadas de hogar nunca han sido destinatarias de medidas de fomento de empleo a través de beneficios cotizatorios, los

\footnotetext{
${ }^{38}$ Rodríguez Cardo, I.A., “El nuevo sistema especial de empleados de hogar...”, op.cit., p.192.

${ }^{39}$ Real Decreto 24/1989, de 13 de enero, por el que se establecen las normas básicas de cotización a la Seguridad social, desempleo, fondo de garantía salarial y formación profesional durante 1989.

${ }^{40}$ Luján Alcaraz, J., El Régimen Especial de la Seguridad Social de los Empleados de Hogar, op.cit., p.77.
} 
cuales fueron inexistentes hasta la Ley 40/2003, de 18 de noviembre, desarrollada por el RD 1621/2005, de 30 de diciembre, que instauró una reducción de la cotización para la contratación de empleadas de hogar por las familias numerosas.

La DA 39a de la Ley 27/2011, de 1 de agosto, vino a transformar profundamente este escenario, pues no sólo implicó que la obligación de cotizar recayese exclusivamente sobre el empleador independientemente de la modalidad del servicio recibido. Para alcanzar la plena convergencia, se implantaría un régimen de cotización que si bien no responde a la retribución que individualmente reciben las empleadas -al menos, durante la aplicación del periodo transitorio (que se extiende hasta el año 2019)-, sí vendría a determinar la cuota que se deberá satisfacer.

Se establecería de este modo una escala integrada por quince tramos, cada uno de ellos indicador de una determinada retribución mensual que incluye la prorrata de pagas extraordinarias, de modo que el salario que recibía determinaba la ubicación en un concreto intervalo, que indicaba la base de cotización por la que se debía cotizar. Se iniciaba el camino hacia el logro de unas carreras cotizatorias parejas a los salarios reales, determinantes de las prestaciones a percibir.

Pero como hemos advertido, el RD-Ley 26/2012, de 28 de diciembre, incidiría en esta aplicación paulatina buscando aumentar de forma acelerada e inmediata el coste social de las empleadas, lo que se conseguiría alterando dos elementos en los que se basaba el régimen transitorio descrito. De un lado, fusionando varios de sus tramos, pasando a reducirse a un número de ocho, elevándose por consiguiente la base de cotización correspondiente a cada uno de ellos, con una mayor intensidad en los situados en las primeras posiciones, esto es, para las retribuciones de menor cuantía -los pretéritos tramos primero a tercero quedaron refundidos en uno solo en la nueva escala-, y para aquellos que se encontraban en la parte inferior de cada uno de los tramos. Además, se introduciría el tramo octavo, de cuantía más elevada que su equivalente predecesor, con lo que se originó “unos resultados variables según la retribución real de cada trabajador" ${ }^{41}$, y ello porque determinados empleadores se beneficiaron de tal modificación -aquellos cuya empleada reciba un salario superior a la base estimada-, mientras que otros se vieron más perjudicados -aquellos que debían calcular la cuota sobre una base de cotización superior, en menor o mayor medida, a la retribución de su empleada, especialmente, por la eliminación de los tres primeros tramos-. De otro lado, se modificó la forma de actualizar las bases de cotización, pasándose a tomar un parámetro distinto: en función del incremento que experimente el salario mínimo interprofesional para los años 2014 a 2019. Modificaciones que fueron valoradas negativamente ${ }^{42}$, especialmente para las empleadas a tiempo parcial por horas, pues se hacía evidente que la nueva regulación se dirigía a la búsqueda de una mejora recaudatoria, presagiándose que el establecimiento del salario de la empleada vendrá

\footnotetext{
41 Blasco Rasero, C., "El sistema especial de empleados de hogar y el proceso de homogeneización”, Aranzadi Social, núm. 4, 2013.

${ }^{42}$ Sanz Sáez, C., La protección social de las empleadas de hogar, Editorial Bomarzo, 2017, p. 94.
} 
precedido de "un atento estudio de los tramos para establecer aquél que resulte más favorable a efectos de cotización" 43 . Es por ello que desde el principio se proponía la aplicación directa de las bases de cotización reales igual que en el RGSS, estableciendo un mecanismo sencillo para que el empleador pueda comunicar las variaciones que se produzcan.

A fin de calcular la cuota de cotización a ingresar, a tales bases de cotización les serán de aplicación un tipo de cotización que, con la reforma del 2011 dejaría de ser único e invariable para desglosarse en función de las contingencias protegidas, llevándose a cabo, también en este aspecto, el proceso de homogeneización. De esta forma, a la base de cotización se aplicará el porcentaje correspondiente a las contingencias comunes y profesionales, estableciéndose para la primera una modulación anual para lograr la plena equiparación con el Régimen General en el año 2019. Junto a ello, debemos añadir la cotización correspondiente a las contingencias de accidentes de trabajo y enfermedades profesionales, aplicándose el tipo de cotización previsto en la tarifa de primas establecidas legalmente, siendo la cuota resultante a cargo exclusivo del empleador. Por lo demás, debemos de tener en cuenta que no existe la obligación de cotizar por el FOGASA ${ }^{44}$, ni tampoco, por la protección por desempleo.

La Ley 6/2018, de 3 de julio, de Presupuestos Generales del Estado para el año 2018, dilató la vigencia del periodo transitorio hasta el año 2023 (apartado seis de la disposición final cuadragésima). Tal medida implicaba una postergación de la convergencia entre la cotización y los salarios realmente percibidos que resulta criticable en la medida que se mantiene un tratamiento diferenciador que perjudica el disfrute de los derechos prestacionales. Se optaba por atender a las dificultades económicas que para el hogar familiar supone formalizar la relación laboral por la vía del aplazamiento de la efectividad de los derechos de las trabajadoras. La equiparación progresiva del tipo de cotización seguía, en cambio, su curso, manteniéndose que " $a$ partir del año 2019, el tipo de cotización y su distribución entre empleador y empleado serán los que se establezcan con carácter general, en la respectiva Ley de Presupuestos Generales del Estado, para el Régimen General de la Seguridad Social”. Por su parte, el Real Decreto-ley 28/2018, de 28 de diciembre, para la revalorización de las pensiones públicas y otras medidas urgentes en materia social, laboral y de empleo, en un intento de corrección, ha modificado sustancialmente el panorama creado por la LPGE del 2018, dando una nueva redacción a la disposición transitoria decimosexta de la LGSS. Con tal reciente regulación tiene lugar un adelanto en el alcance de la convergencia entre la cotización y los salarios que se prevé ahora a partir del 2021, estableciéndose para el año 2019 y 2020 (con la oportuna actualización en idéntica proporción al

\footnotetext{
${ }^{43}$ Fernández Orrico., F.J., "Primer intento de mejora en la gestión del sistema especial para empleados de hogar por RDL 29/2012, de 28 de diciembre”, Revista Justicia Laboral, núm. 53, 2013, pp. 65 y ss.

${ }^{44}$ El artículo 3, letra b), del RD 1620/2011, de 14 de noviembre dispone que: “b) Con carácter supletorio, en lo que resulte compatible con las peculiaridades derivadas del carácter especial de esta relación, será de aplicación la normativa laboral común. Expresamente no será de aplicación el artículo 33 del Estatuto de los Trabajadores".
} 
incremento que experimente el salario mínimo interprofesional), una nueva escala que ha ampliado el número de tramos a diez, apreciándose que la incorporación de tales nuevos intervalos tiene lugar en los tramos superiores de bases de cotización, y no en los inferiores. Podemos destacar dos novedades de esta escala que se encuentra en el artículo 4 del RD-L 28/2018, de 28 de diciembre: la introducción de un décimo tramo en el que a partir de un determinada retribución (en concreto, 1294,01 euros) la base de cotización corresponderá a tal remuneración mensual percibida; y, la incorporación de una columna indicativa del número máximo de horas trabajadas que corresponderán a cada tramo ${ }^{45}$, quizás incluido para hacer frente a la disfuncionalidad detectada por algún sindicato en la TGSS, que admitía que las empleadas de hogar puedan ser dadas de alta con salarios inferiores a mínimo interprofesional para la proporción de horas que marcan sus contratos.

Desde la integración se ha aumentado considerablemente el número de afiliadas: de 110.429 de media en el año 2010 en el Régimen Especial, se incrementa a los 424.403 afiliadas de media en el 2017 en el Sistema Especial. Cuestión distinta es que se haya logrado los objetivos marcados de recaudación. Y, aunque la tasa de informalidad sigue situándose en un alarmante $30 \%{ }^{46}$, quizás la vía más adecuada se encuentre en reducir los costes que de la formalización de la relación derivan.

Al respecto y, salvo el islote que mencionaremos a continuación, las empleadas de hogar nunca han sido destinatarias de las medidas específicas de fomento de empleo. Sería la reforma del 2011 la que introduciría un régimen de beneficios a las cuotas, caracterizado por su carácter transitorio y su escasa entidad, lo que hacía anticipar su parca trascendencia para evitar el tránsito o permanencia en la no declaración de la relación laboral. La doctrina especializada subraya que una mayor incidencia en la opacidad que caracteriza a esta actividad se lograría, en lugar de incentivar y bonificar a la Seguridad Social, con el establecimiento de una deducción específica en el Impuesto sobre la Renta de las Personas Físicas ${ }^{47}$. En materia fiscal sabemos que, el pagador (el

\begin{tabular}{|c|c|c|c|}
\hline Tramo & $\begin{array}{l}\text { Retribución mensual incrementada con la proporción de pagas } \\
\text { extraordinarias } € / \text { mes }\end{array}$ & $\begin{array}{c}\text { Base de cotización } \\
€ / \text { mes }\end{array}$ & $\begin{array}{c}\text { Máximo horas } \\
\text { trabajadas }\end{array}$ \\
\hline $1^{\circ}$ & Hasta 240,00 & 206,00 & 34 \\
\hline $2^{\circ}$ & Desde 240,01 hasta 375,00 & 340,00 & 53 \\
\hline $3^{\circ}$ & Desde 375,01 hasta 510,00 & 474,00 & 72 \\
\hline $4^{\circ}$ & Desde 510,01 hasta 645,00 & 608,00 & 92 \\
\hline $5^{\circ}$ & Desde 645,01 hasta 780,00 & 743,00 & 111 \\
\hline $6^{\circ}$ & Desde 780,01 hasta 914,00 & 877,00 & 130 \\
\hline $7^{\circ}$ & Desde 914,01 hasta $1.050,00$ & $1.050,00$ & 160 \\
\hline $8^{\circ}$ & Desde $1.050,01$ hasta $1.144,00$ & $1.097,00$ & 160 \\
\hline $9^{\circ}$ & Desde $1.144,01$ hasta $1.294,00$ & $1.232,00$ & 160 \\
\hline $10^{\circ}$ & Desde $1.294,01$ & Retribución mensual & 160 \\
\hline
\end{tabular}

46 Según revela el cruce de los datos de afiliados a la Seguridad Social (418.964 afiliados al cierre de 2017) con los de la Encuesta de Población Activa (641.700).

47 En algunas Comunidades Autónomas, si bien, en pocas, se reconocen deducciones por ayuda doméstica. De este modo, en Andalucía, en el artículo 13.3 se prevé de manera específica para las personas con discapacidad, en los siguientes términos: "asimismo, cuando se acredite que las personas con discapacidad necesitan ayuda de terceras personas y generen derecho a la aplicación del mínimo en concepto de gastos de asistencia, conforme a la normativa estatal reguladora del Impuesto sobre la 
empleador) no practica ninguna retención en la nómina, mientras que la empleada tiene el deber (si se da los requisitos para ello) de presentar su declaración de la renta.

Tal régimen de beneficios consiste en una reducción de las cotizaciones en un 20 por ciento por la contratación de las personas que presten servicios en el hogar familiar, y que hayan quedado incorporadas en el Sistema Especial, siempre que la obligación de cotizar se haya iniciado a partir de la fecha de la integración del REEH en el RGSS, limitada a los ejercicios 2012, 2013 y 2014, y a los efectos de la “aportación empresarial a la cotización a la Seguridad Social por contingencias comunes en este Sistema Especial”. Las demandas sociales, y el temor a que descendieran el número de trabajadores ocupados, han llevado a la prórroga de estos beneficios durante los años posteriores, manteniéndose actualmente su vigencia ${ }^{48}$. Sin embargo, como una malversación, la disposición adicional segunda del RD-Ley 26/2012, de 28 de

Renta de las Personas Físicas, el contribuyente podrá deducirse de la cuota íntegra autonómica la cantidad resultante de aplicar el 15\% del importe satisfecho a la Seguridad Social, en concepto de cuota fija que sea por cuenta del empleador o empleadora, de conformidad con lo establecido en el Sistema Especial del Régimen General de la Seguridad Social de Empleados del Hogar de trabajadores fijos, con el límite de 500 euros anuales por contribuyente. Únicamente tendrá derecho a esta deducción el contribuyente titular del hogar familiar que conste como tal en la Tesorería General de la Seguridad Social, por la afiliación en Andalucía al Sistema Especial del Régimen General de la Seguridad Social de Empleados del Hogar de trabajadores fijos, de acuerdo con lo previsto en la normativa de aplicación". En el artículo 14 se regula la "deducción autonómica por ayuda doméstica”: "1. La persona titular del hogar familiar, siempre que constituya su vivienda habitual, y que conste en la Tesorería General de la Seguridad Social por la afiliación en Andalucía al Sistema Especial del Régimen General de la Seguridad Social de Empleados del Hogar, podrá deducirse de la cuota íntegra autonómica del Impuesto sobre la Renta de las Personas Físicas la cantidad resultante de aplicar el 15\% del importe satisfecho por cuenta del empleador o empleadora a la Seguridad Social correspondiente a la cotización anual de un empleado o empleada, con un límite máximo de 250 euros anuales, que será actualizado anualmente conforme a la legislación vigente, cuando concurra cualquiera de los siguientes requisitos en la fecha del devengo del impuesto: a) Que los cónyuges o miembros integrantes de la pareja, inscrita en el Registro de Parejas de Hecho de la Comunidad Autónoma de Andalucía, sean madres o padres de hijos que formen parte de la unidad familiar y que ambos perciban rendimientos del trabajo o de actividades económicas. En este supuesto, podrá aplicarse la deducción la persona titular del hogar familiar o su cónyuge o pareja de hecho. b) Que los contribuyentes sean madres o padres de familia monoparental y perciban rendimientos del trabajo o de actividades económicas. 2. A los efectos de este artículo, se entenderá por titular del hogar familiar el previsto en la normativa reguladora del Sistema Especial del Régimen General de la Seguridad Social de Empleados del Hogar” Decreto Legislativo 1/2018, de 19 de junio, por el que se aprueba el Texto Refundido de las disposiciones dictadas por la Comunidad Autónoma de Andalucía en materia de tributos cedidos.

${ }^{48}$ La última ampliación tuvo lugar con el RD-L 28/2018, de 28 de diciembre, que prevé su aplicación durante el año 2019 que establece: serán beneficiarios de dicha reducción los empleadores que hayan contratado, bajo cualquier modalidad contractual, y dado de alta en el Régimen General a un empleado de hogar a partir del 1 de enero de 2012, siempre y cuando el empleado no hubiera figurado en alta en el Régimen Especial de Empleados de Hogar a tiempo completo, para el mismo empleador, dentro del período comprendido entre el 2 de agosto y el 31 de diciembre de 2011; recordando que la reducción de cuotas se ampliará con una bonificación hasta llegar al 45 por 100 para familias numerosas, en los términos previstos en el artículo 9 de la Ley 40/2003, de 18 de noviembre, de protección a las familias numerosas; y dejando intacto la inaplicación de estos beneficios en la cotización a la Seguridad Social a cargo del empleador, en los supuestos en que los empleados de hogar que presten sus servicios durante menos de 60 horas mensuales por empleador asuman el cumplimiento de las obligaciones en materia de encuadramiento, cotización y recaudación en dicho sistema especial, de acuerdo con lo establecido en la disposición adicional vigésima cuarta del texto refundido de la Ley General de la Seguridad Social (artículo 4.2 del RD-L 28/2018, de 28 de diciembre). 
diciembre, excluyó del régimen de beneficios cotizatorios a aquellos supuestos en los que prestando las empleadas de hogar servicios durante menos de 60 horas mensuales por empleador, asuman el cumplimiento de las obligaciones en materia de encuadramiento, cotización y recaudación en dicho Sistema especial. Expulsión que con el Real Decreto 8/2015, de 30 de octubre, ha sido establecida en la disposición adicional vigésima cuarta, lo que resulta inaceptable pues implicará un retroceso en el afloramiento de la informalidad parcial que afecta gravemente a estos servicios, y que parece sustentar.

Estos beneficios quedaban absorbidos en aquellos supuestos cuyos sujetos destinatarios fueran las familias numerosas, cuyo régimen de reducciones quedó intacto a lo previamente existente -esto es, el $45 \%$ de las cuotas a la Seguridad Social a cargo del empleador ${ }^{49}$-. Por lo que "para las familias numerosas, núcleos importantes de prestación de servicios domésticos, el nuevo régimen no tendrá ningún tipo de incentivación respecto al existente con anterioridad a la reforma” ${ }^{50}$.

La existencia de un régimen de bonificaciones en esta actividad la consideramos necesaria por la confluencia de diversos motivos, que nos llevan a demandar que los mismos adquieran una vigencia permanente. El primero de ellos, porque la integración en el Régimen General ha supuesto para el empleador una elevación de los costes sociales. Si consideramos que se tratan de servicios destinados al hogar familiar, a los que se acuden ante una insuficiente red de servicios públicos, tiene lugar una privatización del coste que pasa a ser asumido por las familias, por lo que el establecimiento de beneficios en la cotización deviene imprescindible. En segundo lugar, y correlativo a la anterior, desde la perspectiva del fomento de empleo, y ello porque a consecuencia de la regulación jurídica laboral, eran las trabajadoras las que debían asumir el coste de la cotización, siendo ésta una de principales razones de la informalidad señalada. El traspaso de esta obligación a los empleadores puede ser, nuevamente, un factor para mantenerlas en tal situación de invisibilidad, es por ello que el apoyo al presupuesto económico de la familia devendrá esencial para lograr el afloramiento de estas empleadas, y creemos también, para la creación de nuevos empleos, como efecto del incremento de la valoración social que todos estos avances significarán para la actividad (ello especialmente, si se acompaña de medidas de información que se lleven a cabo de forma continuada). Y, finalmente, porque consideramos que es una vía para mejorar la protección social de las empleadas, y ello porque existiendo el riesgo latente de que tales costes sociales se obtengan mediante una absorción de la retribución de las empleadas, la disponibilidad de estos beneficios vendría a constituir una garantía en el mantenimiento y mejora de las remuneraciones de

\footnotetext{
49 Artículo 9 de la Ley 40/2003, de 18 de noviembre, de protección a las familias numerosas; artículo 5 del Real Decreto 1621/2005, de 30 de diciembre, por el que se aprueba el Reglamento de la Ley 40/2003, de 18 de noviembre, de protección a las familias numerosas; y, apartado segundo de la disposición adicional vigésima cuarta de la LGSS.

${ }^{50}$ García González, G., "La integración del régimen especial de empleados de hogar: logros y retos de futuro”, Aranzadi Social, 2011.
} 
las empleadas de hogar. Todo ello favorecería, entonces, a las bases de cotización, y por ende, el acceso e intensidad de la acción protectora.

\section{4.-LA APERTURA A LAS CONTINGENCIAS PROFESIONALES: EL INICIO DE UN CAMINO INACABADO HACIA LA IGUALDAD}

Desde la primera formulación de la protección a través de la regulación del Decreto de 1969, en el servicio al hogar familiar no se hacía distinción entre contingencias comunes y profesionales. El artículo 22.3 del Decreto de 1969 establecía que “las prestaciones que este régimen concede en caso de accidente serán las mismas que otorgue el régimen General por accidente no laboral”. Esta ausencia de distinción y consiguiente derivación de toda enfermedad y/o accidente a la regulación de aquellas de carácter común, ha supuesto que las empleadas del hogar no disfruten del tratamiento que reciben tales contingencias. Sin duda la cuestión de la seguridad y la salud de las empleadas del hogar y la escasa protección que la ha caracterizado, ha derivado de la infravaloración que reciben las tareas que son realizadas en el contexto de esta relación laboral especial, y de ello, la insuficiente atención que se ha dirigido a los riesgos que llevan aparejados.

En el ámbito laboral, la protección de la seguridad y salud se ubicaba en el artículo 13 del RD 1424/1985, de 1 de agosto -“otras obligaciones del titular del hogar familiar”por el cual, se establecía el deber del empleador de "cuidar de que el trabajo de sus empleados se realice en las debidas condiciones de seguridad e higiene", añadiendo que "la deficiencia grave de estas obligaciones será justa causa de dimisión del empleado”. La aprobación de la LPRL supondría, en cambio, la exclusión expresa del servicio del hogar familiar de su ámbito de aplicación. Se excepcionaba con ello la vocación universal declarada en su exposición de motivos, y por la que extendía su protección a todos los trabajadores respecto de los riesgos originados con ocasión de la realización de un trabajo, independientemente de cuál se trate. Se reiteraba tan sólo el deber del titular del hogar familiar, pero sin añadir nada nuevo de lo ya contemplado en la normativa especial. De este modo se disponía que "la presente Ley tampoco será de aplicación a la relación laboral de carácter especial del servicio del hogar familiar. No obstante lo anterior, el titular del hogar familiar está obligado a cuidar de que el trabajo de sus empleados se realice en las debidas condiciones de seguridad e higiene" (artículo 3.4 LPRL).

La expulsión de la LPRL se amparaba, entre otras razones, en la propia realizada por la Directiva 89/391/CEE, de 12 de junio de 1989, relativa a la aplicación de medidas para promover la mejora de la seguridad y de la salud de los trabajadores en el trabajo, cuya transposición vino a efectuar nuestra normativa nacional. En efecto, su artículo 3, apartado a), que contempla las definiciones de los conceptos a los que les resulta de aplicación la norma comunitaria, dispone que por “trabajador” deberá entenderse 
"cualquier persona empleada por un empresario, incluidos los trabajadores en prácticas y los aprendices, con exclusión de los trabajadores del hogar familiar”.

Se argumentaba que la regulación de la normativa comunitaria fue concebida para un determinado contexto, el empresarial, lo que llevó al legislador a centrarse de manera excesiva en los riesgos laborales propios de sectores masculinizados como la industria o la construcción ${ }^{51}$. Se intentaba entonces, sin éxito, acudir a la singularidad de esta relación laboral especial para justificar tal exclusión.

El instrumento que puede resultar satisfactorio para esta actividad sería la apuesta por una regulación específica en la que tenga cabida la introducción de las particularidades pertinentes, razonables y proporcionables, que atienda a las especiales circunstancias del lugar de prestación de servicios, y como consecuencia de lo anterior, en las que se sitúa el propio empleador, teniendo en cuenta que no es un empresario, y aún si lo fuera en su esfera profesional, debe presumirse que desconoce las cualidades específicas que deben presentar las concretas medidas a adoptar en este empleo para que sean eficaces, como medio para impulsar el cumplimiento de sus obligaciones, así como, las de las propias empleadas.

En definitiva la especialidad no debe tomarse como pretexto para eludir la proyección concreta de la prevención de riesgos laborales a esta actividad, como ha ocurrido hasta ahora, sino que ha de servir como cauce que dirige la actuación en este ámbito, que exige de una atención específica que imponga, a la vez que facilite, el cumplimiento de tales responsabilidades derivadas de la contratación de servicios ajenos. Con las reformas del 2011, sin embargo, sólo se logró un avance parcial al centrarse en el contexto prestacional, pues pese a que se ha introducido cierto refuerzo formal en la responsabilidad del empleador, lo cierto es que nada se ha hecho para lograr su plasmación real, lo que hace presagiar un limitado, sino inexistente, alcance real de la prevención. A esto contribuye las dificultades de control por parte de la ITSS, dado que al desarrollarse la prestación de servicios en el hogar familiar "deberán obtener su expreso consentimiento o, en su defecto, la oportuna autorización judicial” ${ }^{52}$.

Con el RD 1620/2011, de 14 de noviembre, se perdería la oportunidad de incidir en esta injustificable situación, que no supone sino una total inadvertencia hacia los derechos sociales y también fundamentales de la empleada del hogar. De este modo, pese a que con la actual regulación parece que el legislador ha querido otorgarle una mayor importancia, como decimos, al menos con carácter formal, el contenido de tal deber sigue formulándose con la misma escasa intensidad que en la regulación predecesora. El artículo 7 dispone que "el empleador está obligado a cuidar de que el trabajo del empleado de hogar se realice en las debidas condiciones de seguridad y salud", añadiendo como novedad que, "para lo cual adoptará medidas eficaces, teniendo debidamente en cuenta las características específicas del trabajo doméstico", lo que

\footnotetext{
${ }^{51}$ Martínez Yáñez, N.M, “Algunas consideraciones sobre igualdad por razón de género en el marco de la seguridad y salud en el trabajo”, Lan Harremanak, núm.25, 2012, p. 182.

52 Artículo 13.1 de la Ley 23/2015, de 21 julio, de la Inspección de Trabajo y Seguridad Social de 2015.
} 
viene a reforzar tal obligación, pues no bastará con cualquier medida, sino que se exige que éstas sean eficaces; de forma que un incumplimiento grave de tales obligaciones será justa causa de dimisión de la empleada (en cuyo caso, entendemos, se aplicará el art. $50 \mathrm{ET}$, reconociéndose en su caso la indemnización correspondiente al despido improcedente, eso sí, en la cuantía prevista en el artículo 11 del RD 1620/2011, de 14 de noviembre). Sigue reconociéndose una amplia discrecionalidad al empleador para la concreción específica del contenido que debe alcanzar el deber y del derecho a la seguridad y salud, y aunque en apariencia parece haberse introducido cierta delimitación, reforzando tal obligación, no se facilita su cumplimiento. No nos parece admisible que pueda presumirse que los empleadores o las propias empleadas conocen las medidas eficaces que garantizan la seguridad y la salud en el empleo, y que finalmente su actuación resulte sometida a lo que deba entenderse por "diligencia propia de un buen padre de familia" ${ }^{33}$. Acudir al perfil subjetivo de esta actividad supondría redundar en la idea de que tratándose de trabajos domésticos son predecibles los riesgos que comúnmente pueden acaecer, siendo difícil el reconocimiento de que en la misma se pueda ocasionar riesgos de carácter profesional. Por el contrario, la elevación material de la consideración laboral de este empleo, requiere de una mayor profundización en estudios que detecten los concretos y específicos riesgos que pueden surgir por la propia tipología de servicios y por el lugar de su desarrollo, que deben motivar, insistimos, tras la previa inclusión en la LPRL, o al menos, excluyendo a tal colectivo pero anunciando, como ocurre para otras actividades, que su contenido inspire la normativa específica que se dicte atendiendo a tales circunstancias y a los propios destinatarios de la mismas, esto es, tanto al empleador, impulsando su implantación, como a la empleada, fomentando su cumplimiento. Al respecto, con especial incidencia, por la dimensión de género, en relación con las situaciones de acoso se ha señalado que "las mujeres que trabajan como internas y como externas pero con jornada continua para una sola familia tienen más probabilidad de sufrir este tipo de acoso. Además, la vulnerabilidad es mayor cuando las mujeres son jóvenes y están en situación administrativamente irregular" ${ }^{54}$. El Parlamento Europeo ha indicado que "las mujeres migrantes que aceptan empleos temporales poco cualificados al margen del mercado de trabajo o trabajos como empleadas domésticas pueden estar expuestas a una doble discriminación, ya que, además de que a menudo sus condiciones de trabajo son malas e irregulares -cuando no ilegales-, son más propensas a ser maltratadas o sometidas a violencia o a abuso sexual” ${ }^{55}$.

El Convenio de la OIT núm. 189 reconoce el derecho " $a$ un entorno de trabajo seguro y saludable”, lo que supone un importante avance, pues ordena expresamente a los Estados miembros a que adopten las medidas eficaces, de acuerdo con la legislación y la práctica nacional, a fin de asegurar tales derechos en la relación de trabajo, y para ello

\footnotetext{
${ }^{53}$ STSJ de Madrid, núm. 280/2018, de 17 de abril de 2018.

${ }^{54}$ Cáritas, El empleo de hogar en Andalucía. Diagnóstico y herramientas, Cuadernos de formación núm.56, 2009, pp. 69-71.

${ }^{55}$ PARLAMENTO EUROPEO, Resolución de 19 de octubre de 2010, sobre las trabajadoras en situación precaria.
} 
se deberá tener "debidamente en cuenta las características específicas del trabajo doméstico” (artículo 13). La Recomendación establece más detenidamente medidas para garantizar las condiciones mínimas de seguridad y salud cuando se suministren alojamiento y alimentación -artículo 17- y de los derechos específicos de seguridad y salud -artículo 19-. Se trata de una regulación mucho más comprometida, que se convierte en uno de los aspectos determinantes a abordar por España cuando decida ratificar el Convenio, o antes, lo cierto es que no es necesario ratificarlo para poner fecha al cumplimiento de lo que resulta imperativo por mandato constitucional.

El Parlamento Europeo ha pedido a la Comisión que "evalúe la exención contemplada en la Directiva 89/391/CEE relativa a la mejora de la seguridad y la salud de los trabajadores en el trabajo" ${ }^{\text {"6 }}$, incidiendo en que deberían garantizarse las mismas disposiciones en materia de seguridad y salud en el trabajo para todos los trabajadores domésticos y cuidadores con independencia del tipo de empleo, esto es, tanto si son trabajadores contratados formalmente como si son trabajadores contratados directamente por hogares; y solicitando a los Estados miembros, junto con los interlocutores sociales, que tomen medidas para establecer un sistema de inspección adecuado e idóneo, que sea coherente con el artículo 17 del Convenio de la OIT núm. 189, así como sanciones apropiadas para cuando se infrinja la normativa relativa a la salud y la seguridad en el trabajo. A nivel nacional, a las carencias detectadas se une la dificultad que encuentra en España el desarrollo de la negociación colectiva, cuyo impulso permitiría cubrir la laguna aquí tratada entre otras carencias, en especial, en cuanto a la delimitación de las diversas categorías y grupos profesionales, lo que favorecería a su vez, la formación y profesionalización de la actividad o, las dificultades para inspeccionar, como hemos mencionado anteriormente.

Es en el plano del sistema de Seguridad Social en el que encontramos un verdadero avance en materia de protección de la seguridad y salud de las empleadas de hogar. En la regulación social la no distinción entre contingencias comunes y profesionales no encontraba otra justificación, y ésta sin ser expresa, sino la de evitar al empleador, y en su caso a las propias empleadas, un mayor peso cotizatorio. Ello ha supuesto durante la vigencia del REEH, especialmente una vez superado el reconocimiento de la naturaleza laboral de la prestación, la imposibilidad de que las empleadas del hogar pudiesen disfrutar del tratamiento más ventajoso de las contingencias profesionales, obstaculizando su acceso en numerosas ocasiones a las prestaciones cuando no reunían los requisitos necesarios para hacerlo en base a la consideración común que se atribuía a toda contingencia, pese a que la materialización del riesgo fuese claramente profesional, lo que suponía una desigualdad de trato difícil de justificar.

El inicio de la apertura gradual del recorrido hacia el reconocimiento de las contingencias profesionales, pese a que aún se encuentra inacabado, podemos situarlo

\footnotetext{
${ }^{56}$ PARLAMENTO EUROPEO, Informe "sobre las trabajadoras domésticas y las cuidadoras en la UE" (2014/2094(INI)), de 5 de abril de 2016, p. 17.
} 
en la extensión a esta actividad de las contingencias derivadas del riesgo durante el embarazo y durante la lactancia natural. Este proceso se iniciaría con la LOIEMH, cuya disposición adicional decimoctava, apartado veinte, modificaría la LGSS para hacer extensible la regulación de tales prestaciones a los trabajadores por cuenta ajena de los regímenes especiales, y por tanto al servicio al hogar familiar, reforzándose tal aplicación por la configuración del artículo 1.1 del RD 295/2009, de 6 de marzo, que extiende su ámbito de aplicación a todos los regímenes del sistema de Seguridad Social. Dilatación que supuso el reconocimiento implícito de los riesgos de carácter laboral en los que se encontraba la empleada del hogar, si bien, en un primer momento, como en términos generales ha estado marcada la prevención de riesgos laborales en óptica de género, impulsado por la protección que merece la maternidad.

No obstante, queremos destacar que la actuación llevada a cabo se mostró insuficiente si atendemos a las posibilidades que pudo adoptar dada la base jurídica de la que disponía. Incluso podemos considerar que la extensión que llevó a cabo se debió más bien a que el reconocimiento de tales prestaciones tenía que alcanzar a todas las trabajadoras sin excepción, incluidas las empleadas del hogar, pues otro posicionamiento sería contrario a los principios que defiende; pero no desde la óptica que permita vislumbrar de tal medida el punto de partida hacia un mayor compromiso en esta materia, es decir, en la extensión de la protección de las contingencias profesionales.

Por lo que respecta al reconocimiento de estas prestaciones, queremos subrayar que el principal escollo se encuentra en la extensión a esta actividad de la definición de la situación protegida: “se considera situación protegida el periodo de suspensión del contrato de trabajo en los supuestos en que, debiendo la mujer trabajadora cambiar de puesto de trabajo por otro compatible con su estado, en los términos previstos en el artículo 26, apartado 3, de la Ley 31/1995, de 8 de noviembre, de Prevención de Riesgos Laborales [apartado 4, respecto al riesgo durante la lactancia natural], dicho cambio de puesto no resulte técnica u objetivamente posible, o no pueda razonablemente exigirse por motivos justificados" (artículo 186 y 188 LGSS). Ello supone que la protección de las trabajadoras embarazadas o en lactancia natural tiene como ámbito objetivo el fijado en el artículo 3 LPRL, del que quedan excluidas las empleadas del hogar. Como hemos tenido ocasión de incidir, la exclusión de la LPRL y la carencia de una normativa que especifique los riesgos alcanza en esta materia. Debe de tenerse en cuenta que las disposiciones de la Directiva 89/391/CEE, de 12 de junio de 1989, exceptuando el apartado 2 de su artículo 2, son de plena aplicación a la totalidad del ámbito a que se refiere el artículo 1, apartado 1, de la Directiva 92/85/CEE del Consejo, de 19 de octubre de 1992, relativa a la aplicación de medidas para promover la mejora de la seguridad y de la salud en el trabajo de la trabajadora embarazada, que haya dado a luz o en período de lactancia, y como hemos señalado, se excluye a los trabajadores al servicio del hogar familiar. Como hemos avanzado, es necesario una urgente revisión de toda esta materia, a fin de garantizar y aplicar un nivel adecuado de salud y seguridad en el trabajo, en especial, en relación con la protección de la maternidad 
Habiéndose reconocido el derecho a acceder a tales prestaciones el principal problema deriva en última instancia de la exclusión del campo de aplicación de la LPRL y, correlativamente, de los inconvenientes para la aplicación de los deberes establecidos en su artículo 26, cuyo régimen escalonado de obligaciones finaliza con la adopción de la medida consistente en la suspensión del contrato. Lo cierto es que sin desconocer la complejidad de una hipotética aplicación en el hogar familiar, entre otros motivos, porque no existe una definición de las funciones en esta actividad, la exclusión de la LPRL parece legitimar su no extensión a esta actividad. El acceso a la suspensión y la correspondiente prestación derivaría de las previsiones en el ET y LGSS, así como, del Real Decreto 295/2009, de 6 de marzo ${ }^{57}$, el cual sigue estableciendo una diferenciación en su tratamiento en función de si la empleada presta sus servicios con carácter exclusivo o no, a un hogar familiar, que resulta censurable y por lo que solicitamos la introducción de las correcciones pertinentes para adaptar la regulación al contexto derivado del Sistema Especial. No obstante, y si bien, debemos rechazar tal regulación por inadaptada al nuevo contexto, lo cierto es que sí resulta interesante atender, al menos, al elemento en el que se hace recaer la concesión de la prestación. De tal forma, se dispone que cuando se trate de servicios que se presten para un hogar con carácter exclusivo, es necesario una declaración del responsable del hogar familiar sobre la inexistencia de puesto de trabajo compatible con el estado de la trabajadora, por el contrario, cuando no sea exclusivo, es necesario la declaración de la trabajadora sobre la actividad desarrollada. Desde luego que un nulo compromiso en materia de prevención de riesgos laborales no podría suponer un obstáculo para activar la suspensión del contrato y la prestación correspondiente, que aparece entonces como la única alternativa posible.

Por lo demás, debemos hacer referencia a que la obligación de cotización se mantiene durante la percepción de la prestación de riesgo durante el embarazo y durante la lactancia natural (del mismo modo, para la incapacidad temporal, maternidad y paternidad), debe entenderse, por parte del empleador. No obstante, en aquellos supuestos en los que la empleada de hogar preste sus servicios durante menos de 60 horas mensuales por empleador y hubiera acordado con este último la asunción de las obligaciones en materia de encuadramiento, durante las situaciones de incapacidad temporal, maternidad, paternidad, riesgo durante el embarazo y riesgo durante la lactancia natural, la entidad gestora o colaboradora de la Seguridad Social a la que corresponda el pago del respectivo subsidio descontará de éste el importe de la totalidad de la cotización a la Seguridad Social que proceda en dichas situaciones. El descuento se realizará tanto de la cuota correspondiente a la trabajadora como la del empleador, lo que de ser de tal modo nos resultaría inaceptable. Es necesario recordar que el empleador debe hacerse cargo de la cuota (tanto por contingencias comunes como profesionales), aun cuando se encuentre en suspenso el contrato, pues la obligación de

\footnotetext{
${ }^{57}$ Real Decreto 295/2009, de 6 de marzo, por el que se regulan las prestaciones económicas del sistema de la Seguridad Social por maternidad, paternidad, riesgo durante el embarazo y riesgo durante la lactancia natural.
} 
cotizar se mantiene, por lo que deberá entregar la cuantía correspondiente a la empleada. No obstante, a fin de evitar equívocos indeseados, hubiera sido más satisfactoria tal indicación aunque ello no hubiera servido para reprochar al legislador lo inconveniente de la solución otorgada. Aunque tal medida pretende justificarse en el intento de facilitar el cumplimiento del ingreso, el legislador asumiendo que la empleada no podrá hacerse cargo de la entrega de la cuota, adopta una solución salomónica y descuenta la misma de la prestación a recibir, bajo la presunción de que el empleador le hará entrega de la cuantía que le corresponde sufragar, siéndole indiferente si la empleada efectivamente recibe o no la cuota empresarial en tal momento, ignorando la realidad tras el tipo de prestaciones.

Teniendo como base la Recomendación número 4 del Informe de evaluación y reforma del Pacto de Toledo de 2010, la Ley 39/2010, de 22 de diciembre, de Presupuestos Generales del Estado para el año 2010, vino a culminar el proceso de equiparación en cuanto al alcance de la distinción entre contingencias comunes y profesionales, avanzando en la convergencia de las condiciones de protección, y cuyo desarrollo tuvo lugar con el RD 1596/2011, de 4 de noviembre ${ }^{58}$.

No obstante se excluye el régimen de responsabilidades en orden a las prestaciones, sin duda, por la especial consideración que el Sistema Especial concede al empleador, que deberá reintegrar la cantidad correspondientes a las cotizaciones atrasadas más los recargos, como la correspondiente sanción administrativa conforme a la LISOS, lo que parece que adquiere un carácter suficientemente disuasorio.

Por lo que respecta al recargo de las prestaciones económicas la LGSS no se pronuncia en relación con el artículo 164 LGSS, por lo que su contenido debe ser de aplicación. Sin embargo, pueden surgir dudas en la medida en que el artículo 3.2 RD 1596/2011, de 4 de noviembre, impuso la inaplicación de tal precepto. En todo caso, lo cierto es que en relación con las posibilidades reales de acceder al recargo de prestaciones, las mismas se encuentran condicionadas al incumplimiento de obligaciones específicas determinadas por el empleador en materia de seguridad y salud, por lo que es difícil su reconocimiento en relación con la amplia habilitación con la que cuenta para dar por satisfecho su deber en seguridad y salud, y ello por más que se exija que las medidas a adoptar deban revestir de eficacia.

\section{5.- LA ACCIÓN PROTECTORA DEL SISTEMA ESPECIAL DE EMPLEADAS DEL HOGAR}

Con la integración y creación del Sistema Especial tuvo lugar una innegable mejora en la formulación jurídica de la acción protectora, lográndose una convergencia con el

\footnotetext{
58 Real Decreto 1596/2011, de 4 de noviembre, por el que se desarrolla la disposición adicional quincuagésima tercera de la Ley General de la Seguridad Social, texto refundido aprobado por el Real Decreto legislativo 1/1994, de 20 de junio, en relación con la extensión de la acción protectora por contingencias profesionales a los trabajadores incluidos en el Régimen Especial de la Seguridad Social de los Empleados de Hogar.
} 
Régimen General. Sin embargo, pese a la declaración expresa de que las empleadas del hogar tendrán derecho a las prestaciones "en los términos y condiciones establecidos en el Régimen General”, las particularidades que se incluyeron seguían careciendo de razonabilidad -cuestionables, como señalamos, desde las excepciones que permite el artículo 11 LGSS- por lo que se mantiene vigente la tradicional e injustificable, por lo discriminatorio de su tratamiento, menor protección de las empleadas del hogar.

Por lo que respecta al acceso a las prestaciones en los supuestos de realización de servicios de forma parcial (independientemente de la línea marcada por el RD-L 29/2012, de 28 de diciembre, que lo es tan solo a los efectos de determinación del sujeto que asumirá las obligaciones en cuanto al encuadramiento y cotización), durante el periodo de 2012 a 2018 (es decir, el que abarca el periodo de aplicación gradual de las normas de cotización), a los efectos de determinar el coeficiente de parcialidad a que se refiere la regla a) del artículo 247 LGSS, las horas efectivamente trabajadas se determinarán en función de las bases de cotización que resulten aplicables en cada momento, divididas por el importe fijado para la base mínima horaria del Régimen General, prescindiendo con ello de exigencias acreditativas o documentales que pueden generar dificultades a los fines de su concreción. La LPGE 2018 procedió a dilatar hasta el año 2023 esta regla y, posteriormente, el RD-L 28/2018, de 28 de diciembre, retocaba de nuevo la redacción, estableciendo una vigencia hasta el año 2020.

Si ya hemos mencionado lo generalizado de la prestación de servicios en jornadas parciales, debemos valorar el alcance que para el servicio al hogar familiar puede implicar el avance en materia de protección social del trabajo a tiempo parcial, pues toda mejora en la protección social de esta modalidad contractual resulta especialmente importante para las empleadas de hogar, pues será más factible acceder a la acción protectora del sistema. Nos referimos a la regulación resultante tras la importante STJUE de 22 de noviembre de 2012, en el asunto Elbal Moreno, que declaró discriminatoria por razón de sexo la regulación entonces existente, y de la que sería resultado los actuales artículos 245 a 248 LGSS. Quizás pueda ser identificada como una medida externa -de las propias del Sistema Especial- que permita incentivar la incorporación y mantenimiento en el sistema de Seguridad Social.

\section{1.- La protección de la incapacidad temporal: debilidades y fortalezas}

De los efectos de la integración en relación con la acción protectora, es la prestación por incapacidad temporal aquella en la que el tratamiento unitario entre contingencias comunes y profesionales alcanzó mayor repercusión. Pero no solo en este aspecto se encontraban los elementos divergentes que hicieron del régimen de esta prestación un factor más en la caracterizadora y tradicional menor protección de las empleadas del hogar. Con la Ley 27/2011, de 1 de agosto, se logró una plena equiparación con el resto de trabajadores por cuenta ajena, desde el punto de vista de la empleada, dado que, en cuanto a las obligaciones del empleador en relación con tal prestación, se añaden 
determinadas matizaciones. En todo caso, la doctrina no ha dudado en calificarla como una de las modificaciones de mayor trascendencia ${ }^{59}$ y calado $^{60}$ en el SEEH en relación con el anterior régimen.

En la regulación preexistente, junto a los tres requisitos genéricos con cierta repercusión específica en el REEH -estos son, estar afiliadas, en alta, o situación asimilada al alta, al sobrevenir la situación protegida, y estar al corriente en el pago de las cuotas-, la concesión y disfrute de la prestación por incapacidad temporal quedaba configurada por un régimen que resultaba inaceptable al apartarse de forma inconcebible de la solución que ofrecía el RGSS, causando indudables perjuicios a las empleadas del hogar. De nuevo la latente justificación en la menor cotización que se realizaba desde el Régimen Especial no validaba un tratamiento desigualatorio y discriminatorio respecto a los demás trabajadores.

La primera de tales especialidades se encontraba en la existencia de un periodo de espera que se dilataba a veintiocho días a partir del inicio de la enfermedad o del accidente, lo que dejaba a la empleada en una situación de innegable desamparo económica, especialmente para aquellas de corta duración cuando acaecía tales contingencias, reprochable para las de carácter común -que en el régimen general comienza a percibirse "a partir del día cuarto de baja en el trabajo" (artículo 173.1, párrafo segundo, LGSS)-, inaceptable para las profesionales -que comienza a percibirse “desde el día siguiente al de la baja en el trabajo” (artículo 173.1, párrafo primero, LGSS)-. Se planteaba como posible argumento a tal divergencia, la carga que implicaba para el empleador la asunción del abono de la prestación "desde los días cuarto al decimoquinto de baja, ambos inclusive”, y a cargo de la Seguridad Social a partir del decimosexto día de baja. Sin embargo, el resultado era desproporcionado y claramente atentatorio al principio de igualdad y no discriminación, y ello porque se buscaba una plena dispensa económica del empleador que se intensificada cuando se trataba de una empleada de las catalogadas como internas. Esto último a causa de la regla prevista en el artículo 16.2 del Decreto de 1969, consistente en que las cuotas correspondientes al mes en que la empleada de hogar pasase a una situación de incapacidad temporal, y las de los meses en que permaneciera en ella, debían de ser abonadas íntegramente por las empleadas, lo que suponía una total exoneración de los costes laborales del empleador. Como decimos, especialmente, para los supuestos de empleadas internas, las cuales debían soportar la ausencia tanto de remuneración como de una prestación económica con un mayor perjuicio al tener que asumir el pago de tales cuotas. Esta finalidad de liberación económica del empleador en base a que es inasumible para las familias contratantes el doble coste que suponía tal situación de baja laboral -que implica el aumento del gasto para las familias empleadoras, dado que en caso contrario debían de soportar el pago de la cotización junto a la remuneración de otra empleada que vendría a suplir los servicios que se han dejado de satisfacer, o aún sin proceder a una nueva

\footnotetext{
${ }^{59}$ García González, G., “La integración del régimen especial de empleados de hogar...”, op.cit.

${ }^{60}$ Vela Díaz, R., El nuevo Régimen de las Personas Empleadas de Hogar: aspectos laborales y de Seguridad Social, Laborum, 2012.
} 
contratación, y una privación de recursos económicos para la empleada incapacitada para trabajar-, sólo podría haber justificado una intervención pública a fin de cubrirlos total o parcialmente.

Con la creación del Sistema Especial tales diferencias se reducen, de modo que se procedió a equiparar el periodo de carencia al existente en el Régimen General con la consecuente distinción entre contingencias comunes y profesionales, por lo que la prestación económica pasa a percibirse a partir del cuarto día en caso de enfermedad común o accidente no laboral, y desde el día siguiente al de la baja médica en el trabajo en caso de accidente de trabajo o enfermedad profesional. En cuanto al sujeto responsable del abono de la prestación, lo será el empleador desde el cuarto día de la baja en el trabajo hasta el octavo ambos incluidos ${ }^{61}$, lo que supone cinco días de salario, a diferencia del Régimen General en el que el abono del subsidio entre los días 4 a 15 de baja en el trabajo, ambos inclusive, se atribuye al empresario (de conformidad con el párrafo segundo del artículo 173.1 LGSS), y posteriormente el pago efectuado directamente por la entidad a la que corresponda la gestión, sin que resulte de aplicación la figura del pago delegado prevista en el Régimen General por el artículo 102.1, letra c), LGSS, tal y como dispone expresamente el artículo 251, letra b), LGSS. Tal reducción conlleva la introducción de una especialidad que, sin embargo, nos parece razonable, porque implica que el legislador ha tenido en cuenta el perfil del empleador imputándole ciertos costes laborales, sin que sean excesivos o desproporcionados, asumiendo el sistema parte de los mismos, y ello logrando una equiparación en la acción protectora de las trabajadoras. Es en esta materia, posiblemente la única, donde la introducción de especialidades justifica la adopción de un Sistema Especial para el proceso de integración. Si se trata de contingencias profesionales, ya vimos que el artículo 251 LGSS, señala que las empleadas de hogar tendrán derecho a las prestaciones en los "términos y condiciones establecidos en el Régimen General de la Seguridad Social”, estableciendo como única particularidad la relativa al régimen de responsabilidad del artículo 167 LGSS, ya analizado. Ello implica que el régimen aplicable sea el previsto para el resto de trabajadores por cuenta ajena, lo que supone que el subsidio se abonará desde el día siguiente al de la baja en el trabajo, estando a cargo del empleador el salario íntegro al día de la baja. Y si se trata de contingencias comunes, a partir del noveno día el empleador deberá cotizar únicamente por la aportación que le corresponda, siendo responsable la entidad gestora o colaboradora del ingreso de la aportación del trabajador.

\footnotetext{
${ }^{61}$ Se deduce que el pago de esos cinco días a cargo del empleador no es al 100 por cien, sino que seguirá las reglas del Régimen General, estas son: del $4^{\circ}$ al $20^{\circ}$ día un $60 \%$ de la base reguladora, y del $21^{\circ}$ día de baja en adelante, el 75\% de la base reguladora, según lo previsto en el artículo 171 LGSS, el artículo 13 del Decreto 1646/1972, de 23 de junio, para la aplicación de la Ley 24/1972, de 21 de junio, en materia de prestaciones del Régimen General de la Seguridad Social, el artículo único del RD 53/1980, de 11 de enero, por el que se modifica el artículo $2^{\circ}$ del reglamento General que determina la cuantía de las prestaciones económicas del Régimen General de la Seguridad Social, respecto a la prestación de incapacidad laboral transitoria (incapacidad temporal), y artículo 2 del Decreto 3158/1966, de 23 de diciembre, por el que se aprueba el Reglamento General que determina la cuantía de las prestaciones económicas del Régimen General de la Seguridad Social y condiciones para el derecho a las mimas.
} 
En cuanto a la subsistencia de la obligación de cotizar durante la incapacidad temporal, ninguna especialidad introdujo la reforma del 2011, por lo que será el titular del hogar familiar el que deba asumir tal cotización, de conformidad con el artículo 144.4 LGSS. Sin embargo, el artículo 3, dos, del RD-L 29/2012, de 28 de diciembre, vino a añadir un nuevo artículo 34 bis, al Reglamento General sobre cotización y liquidación de otros derechos de la Seguridad Social, aprobado por el Real Decreto 2064/1995, de 22 de diciembre, estableciendo para aquellos supuestos en los que la empleada del hogar por prestar menos de 60 horas de servicios por empleador hubiera asumido las obligaciones en materia de encuadramiento y cotización, que durante las "situaciones de incapacidad temporal, maternidad, paternidad, riesgo durante el embarazo y riesgo durante la lactancia natural, la entidad gestora o colaboradora de la Seguridad Social a la que corresponda el pago del respectivo subsidio descontará de éste el importe de la totalidad de la cotización a la Seguridad Social que proceda en dichas situaciones”. La expresión “importe de la totalidad” parece indicar que el descuento se realizará tanto de la cuota correspondiente a la trabajadora como la del empleador, lo que de ser de tal modo nos resultaría inaceptable. Es necesario considerar, siguiendo la lógica que parece haber guiado a la reforma del 2012, que el empleador debe hacerse cargo de la cuota (tanto por contingencias comunes como profesionales), aun cuando se encuentre en suspenso el contrato, pues la obligación de cotizar se mantiene, por lo que deberá entregar la cuantía correspondiente a la empleada.

En todo caso, de esta regulación deriva una situación que con la norma precedente se eludía, tal y como hemos adelantado. En efecto, dado la responsabilidad del empleador de mantener su obligación de cotizar durante el periodo de incapacidad temporal se origina entonces, un aumento de las cargas si, dado la ausencia de la prestación de servicios, debe contratar a otra empleada, lo que será habitual puesto que las necesidades familiares se mantienen -especialmente en caso de menores, enfermos, etc-. Tiene lugar una duplicación de la carga económica que de nuevo resultará difícilmente asumible por la generalidad de las familias, si atendemos al perfil mayoritario que solicitan estos servicios, pues tendrá que cotizar por la persona que se encuentra en incapacidad temporal, y al mismo tiempo, hacer frente a las obligaciones salariales y de Seguridad Social de la nueva persona contratada. Estamos ante una laguna que debe ser cubierta, entendemos, por una actuación homóloga a la previstas en los supuestos de maternidad y paternidad, esto es, que la cotización de la persona que se encuentra de baja, cuando se contrate a otra persona, disfrute de una bonificación del 100 por ciento, a fin de que el titular del hogar familiar no vea duplicado el gasto de la satisfacción de los cuidados de su hogar.

\section{2.- Las pensiones de incapacidad permanente y jubilación: manifestación de una brecha de género sui generis}

Para las pensiones de incapacidad permanente y jubilación, la reforma del 2011 supuso la equiparación plena con el Régimen General, procediendo a su reconocimiento en los 
mismos términos y condiciones que para el resto de trabajadores por cuenta ajena, sometiéndola a única particularidad caracterizada por un matiz transitorio que se extiende hasta el año 2019, aplazado hasta el 2023 por la LPGE del 2018 y, hasta el 2020 con la última de las modificaciones llevadas a cabo por el RD-L 28/2018, de 28 de diciembre, consistente en la exclusión de la aplicación de la figura de la integración de lagunas, por lo que para el Sistema Especial de empleadas de hogar, solo se tendrán en cuentan los periodos efectivamente cotizados en el cálculo de la base reguladora de las pensiones de incapacidad permanente derivadas de contingencias comunes y de jubilación (disposición transitoria decimosexta, apartado cuarto, de la LGSS).

Tal inaplicación conlleva que, desde la entrada en vigor del Sistema Especial hasta la fecha indicada, sólo podrán ser computados los periodos de cotización realmente cotizados, y que por ello, cada uno de los meses en los que no exista cotización se compute en cuantía cero. No nos resulta, desde luego, que la necesaria transitoriedad que requiere la integración de esta actividad pueda justificar la exclusión de un instrumento que dispone de una innegable óptica de género, en la medida en que, precisamente, se dirige a atender a las carreras profesionales que presentan mayores irregularidades cotizatorias, manteniendo la subsistencia de una exclusión que introduce per se un trato peyorativo. Si nos acercamos a los datos, en 2011 (el año de la integración), el número de pensiones de jubilación causadas en el Régimen Especial ascendía a 155.553, siendo en el Sistema especial en el año 2017 de 146.520 pensiones $^{62}$, por lo que podemos concluir que la reforma no ha impulsado, aún, cambios relevantes en el acceso a las pensiones de jubilación. La anterior situación conllevará que la protección de la jubilación deba encauzarse a través de la ofrecida por el nivel no contributivo.

Por lo que respecta a las cuantías de las pensiones, el servicio al hogar familiar se caracterizó por un acceso masivo a las cuantías mínimas. En la actualidad, la situación no ha cambiado, así, los datos del 2017 nos muestran que el 64,71\% de las pensiones de jubilación causadas en el Sistema Especial lo fueron con garantía de mínimo ${ }^{63}$. Desde luego, ello pone de manifiesto el mayor esfuerzo contributivo que todavía se debe propiciar para aproximar las prestaciones, y también no olvidemos, para reducir el acceso a las pensiones no contributivas, cuyo disfrute también tiene un carácter feminizado, especialmente y precisamente, las de jubilación. Como elemento que contribuye a esta situación se encuentra sin duda la postergación de la cotización por los salarios realmente percibidos. En sentido contrario, deberemos estar atentos al impacto que pueda tener en la cotización, el incremento del SMI ${ }^{64}$.

Los datos anteriores nos permiten considerar que las empleadas de hogar es el colectivo que en mayor medida incide en la detectada la brecha de género de las pensiones como

\footnotetext{
${ }^{62}$ Fuente: MITRAMISS.

${ }^{63}$ Fuente: MITRAMISS.

${ }^{64}$ Real Decreto 1462/2018, de 21 de diciembre, por el que se fija el salario mínimo interprofesional para 2019.
} 
la más reciente expresión de la discriminación por razón de sexo en el ámbito concreto de la Seguridad Social que debe ser atendida, tal y como señala las instituciones europeas.

\section{3.-La protección de desempleo: el alcance de una persistente discriminación directa}

En los anteriores apartados hemos abordado las especialidades que se incluyeron en la construcción del Sistema Especial de empleadas de hogar, consistentes en la mutación de algunos de los elementos de la acción protectora, sin embargo, en su formulación también se decidió por la exclusión de la protección dispensada ante una determinada contingencia, específicamente, frente al desempleo. Así lo establece expresamente la letra d) del artículo 251 LGSS, que dispone que la "la acción protectora del Sistema Especial para Empleados de Hogar no comprenderá la correspondiente al desempleo”. Ninguna previsión sobre una actuación futura al respecto se incluiría con la LGSS en su última refundición, a diferencia de lo ocurrió con la Ley 27/2011, de 1 de agosto. En efecto, en esta última norma la expulsión de la acción protectora por desempleo venía acompañada de una vía futura de pronta realización, al establecerse que se adoptarían iniciativas al respecto en el marco de renovación de la relación laboral de carácter especial del hogar familiar. No obstante, la llegada del RD 1620/2011, de 14 de noviembre, ninguna medida dispuso, simplemente se limitaría a señalar, en su disposición adicional segunda, que al mes siguiente de su entrada en vigor, se crearía un grupo de expertos que elaboraría un informe antes de finalizar el 2012, por el que se estudiaría la viabilidad, entre otras materias, de establecer un sistema de protección por desempleo adaptado a las peculiaridades de la actividad del servicio al hogar familiar que garantizara los principios de contributividad, solidaridad y sostenibilidad financiera. Sin embargo, hasta la fecha, ninguna se ha adoptado medida al respecto, por lo que las empleadas de hogar son las únicas trabajadoras por cuenta ajena que quedan excluidas del derecho a la protección por desempleo. La actual ausencia de referencias sobre el planteamiento en términos de igualdad de trato, de una futura extensión a este colectivo, manifiesta la reticencia del legislador de abordar la equiparación en esta materia que, por lo demás, pero no menos importante, implica uno de los principales obstáculos para abordar la ratificación del Convenio núm 189 de la OIT que, como ya señalamos, garantiza en su artículo 14 el disfrute de "condiciones no menos favorables que las condiciones aplicables a los trabajadores en general con respecto a la protección de la seguridad social”.

La doctrina mayoritaria ha calificado de inaceptable tal exclusión desde el momento en que las empleadas del hogar fueron sujetos de una relación laboral, esto es desde 1976 y, sin duda, desde 1985. La renovación jurídica ha originado que se discuta nuevamente por los argumentos de los que se vale el legislador para refrendarla, los cuales siendo inexistentes ha generado una dura crítica doctrinal que sitúa como preferentes las motivaciones de oportunidad política ligadas a la situación económica en la que tuvo 
lugar la reforma, aunque escudados en otras razones. Se trata especialmente de la presunción al fraude que se deriva de la dificultad de controlar este tipo de prestaciones de servicios ante la colisión de derechos fundamentales que se origina y que contribuye a intensificar el trabajo no declarado: se piensa en aquellas situaciones en las que accediéndose a la protección por desempleo, se continúe con la prestación de servicios, en el mismo o diferente domicilio. Las motivaciones basadas en la dificultad de control no son aceptables, tan solo hacen exigible el refuerzo o la adopción de nuevas medidas para evitarlo, se demanda "sistemas efectivos de inspección y control que, garantizando los derechos sociales de los empleados del hogar, respeten los derechos constitucionales a la inviolabilidad del domicilio y a la intimidad personal y familia”65. En nuestra opinión hay que matizar que en esta materia no es que se esté otorgando una protección privilegiada a los derechos fundamentales del hogar familiar, sino que ello se toma como coartada para eludir toda responsabilidad en esta materia.

Una vez justificada la defensa de la extensión de la protección por desempleo, no por ello obviamos que su imperativo reconocimiento deberá afrontar en su configuración, al menos, la dificultad que deriva de la peculiar vía por la que se puede dar por extinguida la relación laboral, esto es, el desistimiento, y ello porque de nuevo, se origina la presunción de comportamientos fraudulentos. Nos planteamos entonces, una vez reconocida la protección por esta contingencia, si el acceso a la misma se podrá originar cuando la extinción haya tenido lugar libremente por el empleador sin justificar causa alguna. Consideramos que sí se deberá permitir el acceso al desempleo, ya que lo contrario, es decir, excluir la pérdida de empleo derivada del desistimiento, dejaría a la empleada en una situación de indefensión y de absoluta subordinación a la decisión del empleador, dado el fundamento en el que se basa esta posible vía de extinción del contrato de trabajo, esta es, poder dar por finalizado el mismo sin alegación de causa en base a la defensa del derecho a la intimidad y del domicilio del empleador, por el cual, no puede ser forzado a una presencia ajena al mismo; entendiéndose que cuando acude a esta vía será porque no concurre ninguna causa que le permita la resolución de la relación a través del despido. En efecto, pudiendo ser la relación extinguida sin concurrir motivo alguno, siempre por decisión del empleador, la empleada se encuentra en la situación protegida por tal contingencia.

Desde luego que las repercusiones de esta discriminación se trasladan más allá del acceso al disfrute per se de la protección por desempleo. De esta forma nos planteamos qué sucede cuando tiene lugar situaciones de concurrencia entre desempleo, maternidad y/o incapacidad temporal, es decir, si procede o no la aplicación de determinados supuestos previstos en los artículos 283 y 284. LGSS. Así, por ejemplo, el artículo 284.2 LGSS dispone que “cuando el trabajador esté percibiendo la prestación por desempleo total y pase a la situación de maternidad o de paternidad, percibirá la prestación por estas últimas contingencias en la cuantía que corresponda”. Se deduce

\footnotetext{
${ }^{65}$ García González “La integración del régimen especial de empleados de hogar...”, op.cit.
} 
que, dado que una empleada de hogar no puede acceder a una prestación de desempleo, tampoco podrá encontrarse en la situación prevista por el mencionado precepto.

La actual exclusión impide el acceso a la prestación por desempleo, tanto del nivel contributivo como del nivel asistencial, así como, a la renta activa de inserción. Por lo que respecta a esta última, tan sólo la concurrencia de otro factor, como es la violencia de género, permitirá a este colectivo el acceso a este nivel de la protección por desempleo. En efecto, y por actuación de la LOPVIG las víctimas de violencia de género que tuviesen acreditada tal condición, es un colectivo que puede acceder a tal protección, y ello tal y como establece el artículo 2 del RD 1369/2006, de 24 de noviembre ${ }^{66}$, "siempre que se reúnan los requisitos exigidos en el apartado 1, excepto los recogidos en los párrafos a) y b)”, estos son: a) ser mayor de 45 años; y b) ser demandante de empleo inscrito ininterrumpidamente como desempleado en la oficina de empleo durante 12 o más meses. Además, y respecto de los restantes requisitos exigidos por el artículo, también se excluye el establecido en su letra c), este es, “haber extinguido la prestación por desempleo de nivel contributivo y/o el subsidio por desempleo de nivel asistencial establecidos en el Título Tercero del texto refundido de la Ley General de la Seguridad Social, salvo cuando la extinción se hubiera producido por imposición de sanción, y no tener derecho a la protección por dicha contingencia", por lo que solo se exige el previsto en la letra d) "carecer de rentas, de cualquier naturaleza, superiores en cómputo mensual al 75 por 100 del salario mínimo interprofesional, excluida la parte proporcional de dos pagas extraordinarias”. De la anterior regulación se deduce, como anticipábamos, que tan solo las empleadas de hogar que sean víctimas de violencia de género podrán acceder a la RAI y ello, especialmente, porque no se les exige la extinción de una prestación por desempleo de nivel contributivo y/o el subsidio por desempleo de nivel asistencial. Pero repárese entonces que el disfrute se consigue no por su condición de trabajadora, sino por su estatus de víctima, de forma que no se produce una complementariedad de factores sino un solapamiento. Supuesto que no es posible extender a la protección por desempleo contemplada en la LGSS, pues recordemos que una de las medidas que se crearon en el contexto de la violencia de género consiste en que las víctimas podrían suspender o extinguir su contrato (artículos 45.1.n) y 49.1.m) ET, respectivamente) considerándose tal situación como de desempleo (artículo 267.1.b). $2^{\circ}$ y, 267.1 $1^{\mathrm{a}}$ ). $5^{\circ}$ LGSS), por lo que si reúne los requisitos pueden acceder a la protección por desempleo (lo que implica además, el disfrute de otros beneficios, tales como, el previsto en el artículo 269.2 LGSS), garantizando con ella la independencia económica de la víctima. Dado que las trabajadoras del servicio al hogar se encuentran excluidas de la protección por desempleo, por derivación, aquellas con el estatus de víctima de violencia de género no podrán disfrutar de los derechos reconocidos y creados por la LOPVIG a nivel prestacional.

\footnotetext{
${ }^{66}$ Real Decreto 1369/2006, de 24 de noviembre, por el que se regula el programa de renta activa de inserción para desempleados con especiales necesidades económicas y dificultad para encontrar empleo.
} 
El legislador social no ha cumplido con el principio de transversalidad de género en la configuración de su régimen protector frente al desempleo. No ha procedido a una revisión de sus postulados tras la elevación de tal principio como derecho constitucional, ni ha procedido a su aplicación en el debate y formulación de reformas posteriores. Todo este panorama nos permite afirmar que la expulsión de las empleadas del hogar del modelo de la protección por desempleo constituye un tratamiento discriminatorio por razón de sexo, que en algunos supuestos resulta ser múltiple.

\section{BIBLIOGRAFÍA}

BLASCO RASERO, C., "El sistema especial de empleados de hogar y el proceso de homogeneización”, Aranzadi Social, núm. 4, 2013.

FERNÁNDEZ ORRICO., F.J., "Primer intento de mejora en la gestión del sistema especial para empleados de hogar por RDL 29/2012, de 28 de diciembre”, Revista Justicia Laboral, núm. 53, 2013.

GALA DURÁN, C., "La protección en materia de seguridad social de los empleados de hogar tras el RDL 29/2012: un viaje de ida y vuelta”, Relaciones laborales y empleados del hogar: reflexiones jurídicas, Espuny Tomás, M.J y, García González, G., Dykinson, 2014.

GARCÍA GONZÁLEZ, G., "La integración del régimen especial de empleados de hogar: logros y retos de futuro”, Aranzadi Social, 2011.

LÓPEZ GANDÍA, J., “La convergencia entre regímenes de Seguridad Social”, Temas Laborales, núm. 81, 2005.

LUJÁN ALCARAZ, J., El Régimen Especial de la Seguridad Social de los Empleados de Hogar, Aranzadi, 2000.

MARTÍNEZ LUCAS, J.A., "La afiliación, altas, bajas y cotización en el Sistema Especial de Seguridad Social para Empleados de Hogar”, Actualidad Laboral, núm. 1314, 2012.

MARTÍNEZ YÁÑEZ, N.M, “Algunas consideraciones sobre igualdad por razón de género en el marco de la seguridad y salud en el trabajo”, Lan Harremanak, núm.25, 2012.

MESTRE I MESTRE, R.M., "Trabajadoras de cuidado. Las mujeres de la Ley de Extranjería”, Mujeres en el camino. El fenómeno de la migración femenina en España, Checa y Olmos, F., (de), Antrazyt, 2005.

MIÑARRO YANINI, M., El trabajo al servicio del hogar familiar: análisis de su nueva regulación, Reus, 2013.

PÉREZ DEL RÍO, T., La valoración del trabajo de las mujeres: aspectos económicos y sociales”, Jornadas para la equiparación de condiciones en el mercado de trabajo: 
Igualdad de condiciones condición de igualdad, AGORA, Institut Catalá de la Dona, Generalitat de Catalunya. Barcelona, 2002.

QUESADA SEGURA, R., "La dignificación del trabajo doméstico. El Convenio núm. 189 OIT, 2011”, Revista General de Derecho del trabajo y de la Seguridad Social, núm. 27, 2011.

QUESADA SEGURA, R., El contrato de servicio doméstico, La Ley, 1991.

RODRÍGUEZ CARDO, I.A., "El nuevo sistema especial de empleados de hogar: una «revolución» inconclusa”, Revista Española de Derecho del Trabajo, núm. 158, 2013.

SÁNCHEZ HUETE, M.A., “ Prevención del fraude fiscal en el contexto de las empleadas del hogar”, Relaciones laborales y empleados del hogar: reflexiones jurídicas, Espuny Tomás, M.J y, García González, G., Dykinson, 2014.

SANZ SÁEZ, C., La protección social de las empleadas de hogar, Editorial Bomarzo, 2017.

VELA DÍAZ, R., Empleo, trabajo y protección social de las mujeres extranjeras en España. Un enfoque de género de la política migratoria, Comares, 2014.

VELA DÍAZ, R., El nuevo Régimen de las Personas Empleadas de Hogar: aspectos laborales y de Seguridad Social, Laborum, 2012.

VICENTE PALACIO, A., "La simplificación de la estructura del sistema de Seguridad Social. El final diferido de un extenuante maratón todavía inacabado”, Economía Española y Protección Social, núm. 4, 2012. 